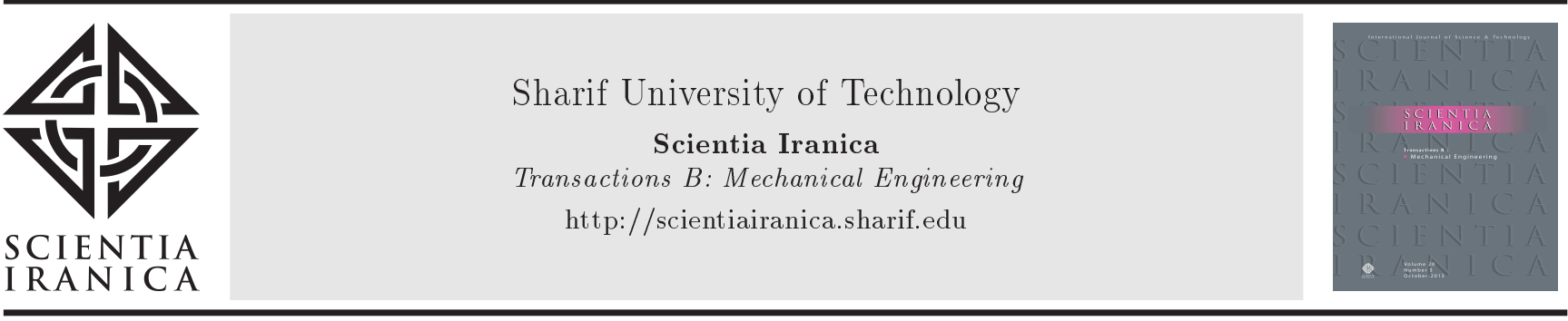

Research Note

\title{
Multivariate adaptive regression spline approach to the assessment of surface mean pressure coefficient on surfaces of C-shaped building
}

\author{
M. Mallick*, A. Mohanta ${ }^{1}$, and A. Kumar \\ Department of Civil Engineering, National Institute of Technology Rourkela, Odisha, India-769008.
}

Received 7 August 2018; received in revised form 2 May 2019; accepted 3 August 2020

\author{
KEYWORDS \\ Angle of incidence; \\ C-shaped building \\ models; \\ Mean pressure \\ coefficient; \\ Surface mean pressure \\ coefficient; \\ Multivariate adaptive \\ regression spline; \\ Wind tunnel test.
}

\begin{abstract}
Proper assessment of wind load ensures a durable design of structures under varying wind load conditions. Accurate prediction of surface mean pressure coefficient $\left(\overline{C_{p}}\right)$ on any irregular plan shaped buildings is essential to assessing wind loads and structural design. The main objective of this study is to present an equation in the line of Multivariate Adaptive Regression Spline (MARS) approach using experimental data of $\overline{C_{p}}$. This developed equation can be used satisfactorily for accurate prediction of $\overline{C_{p}}$ values on the surfaces of C-shaped buildings. Extensive experimentation was carried out to determine the coefficient of pressure over the surfaces of C-shaped building models under varying sizes, corner curvatures, and angles of incidence in a sub-sonic wind tunnel. The predicted values of pressure coefficient of different C-shaped buildings using the developed model were compared with the equations developed by Swami and Chandra (S\&C) and Muehleisen and Patrizi (M\&P). The comparison indicated that the proposed MARS model could predict $\overline{C_{p}}$ values more accurately than S\&C and M\&P models on frontal and side surfaces. Further, the model was used to validate the results using the actual building, and Tokyo Polytechnic University (TPU) data were employed to show the applicability of the proposed equation.

(C) 2020 Sharif University of Technology. All rights reserved.
\end{abstract}

\section{Introduction}

With considerable use of many new innovative building designs, the role of model studies in assessing exactly the wind flow nature and its impact on structures has been realized. As a result, the first important step

1. Present address: Department of Mechanical Engineering, Vellore Institute of Technology Vellore, Tamil Nadu, India-632014.

*. Corresponding author. Tel.: +91-8249497614 E-mail addresses: monalisa.nitrkl@gmail.com (M. Mallick); abinash.mohanta@vit.ac.in (A. Mohanta); akumar@nitrkl.ac.in (A. Kumar) in the wind-induced pressure analysis is to accurately calculate pressure on the walls of structures. Wind pressure on structures are affected by the geometry of the structure, the extent of curved corners, wind angle of incidence, and flow features. The pressure coefficient is required to assess the wind-induced pressure difference. Generally, full-scale structure tests, smallscale model experiments in wind tunnel, and analytical equations are the main techniques, which are mostly required to estimate the pressure coefficient.

A considerable investigation of different structures, i.e., cylindrical [1], rectangular [2], and square, has been reported [3]. Only a few studies have investigated wind pressures on irregular shapes by Cook [4]. Suresh Kumar et al. [5] estimated $C_{p}$ on the faces 
of tall buildings using the model test in wind tunnel. Stathopoulos and Zhou [6,7] studied the wind loads on the stepped roof of L-shape buildings using a numerical approach. Ahmad and Kumar [8] experimented on different types of hip roof plan building models with a $30^{\circ}$ roof slope and examined interferences between the buildings placed in the free air stream at different configurations/angles of incidence. Ho et al. [9] examined the local obstructions on low building wind loads. Lou et al. [10] carried out wind tunnel tests on a doubleskin facade building to determine the wind pressure distribution on each surface. Lu et al. [11] carried out a numerical simulation of spherical tall buildings with and without curved annexes. Chakraborty et al. [12] studied the pressure distribution of ' + ' (plus) shaped tall buildings and compared them numerically by using Fluent. Gomes et al. [13] investigated pressure distributions on L-shaped and U-shaped building models and compared pressure coefficients at different wind incidence angles. Amin and Ahuja [14,15] presented their works on L-shaped and T-shaped buildings with different configurations and estimated the average, minimum, maximum, and root mean square values of pressure coefficients. Kim and Kanda [16] studied fluctuating values of wind pressures, flow separation, and formation of vortex on tall buildings as well as conical buildings. Chakraborty et al. [17] carried out a comparative study of experimental and numerical methods to predict wind effect on ' + ' plan shaped tall buildings. Bhattacharyya et al. [18] measured the pressure distribution of E-shaped tall buildings by varying angles of incidence from $0^{\circ}$ to $180^{\circ}$. Bhattacharyya and Dalui [19] investigated mean wind pressures on E plan shaped tall buildings and compared both experimental and numerical results by Computational Fluid Dynamics (CFD). For a better comparison of the results, pressure contours on all the faces were also predicted by both methods. Yi and $\mathrm{Li}$ [20] investigated a tall building in Hong Kong and used the wind tunnel model test to explain force and pressure coefficients and high frequency balance. The wind tunnel test result was seen to be fairly in agreement with the full model test. $\mathrm{Li}$ and $\mathrm{Li}$ [21] conducted wind tunnel test on $\mathrm{L}$ plan shaped tall buildings to quantify dynamic load across the wind. They proposed an empirical formulation with emphasis on the side ratio and territory of the building to express wind load. Mallick et al. [22] reported the experimental wind tunnel and numerical studies on distribution of pressure coefficient on curved surfaces of the C-shaped building model.

Akins [23], Walton [24], Walker and Wilson [25] proposed parametric equations to predict $C_{p}$ on low height buildings, and Ginger and Letchford [26] and Ohkuma et al. [27] studied the pressure coefficients on a particular building (full-scale) tests by conducting wind tunnel experiments. Swami and Chandra [28] determined average surface pressure coefficients on low height buildings over the building facades. Swami and Chandra [29] proposed an equation ( $\mathrm{S} \& \mathrm{C}$ equation) for the prediction of $C_{p}$ on various heights of rectangular shaped buildings considering the wind direction and side ratio. Grosso [30] proposed a complex parametric model for pressure coefficient around the buildings. The S\&C equation was used to forecast the surface average pressure coefficient $\left(C_{p}\right)$ implemented by Crawley et al. [31] for creating a certain program called Building Energy Simulation. Cook [32] proposed the building codes of common building shapes for estimating a range of average wind pressure coefficients that were further clarified using the analytical wind load calculation techniques. Costola et al. [33] reviewed necessary equations and methodologies for calculating $C_{p}$ by numerical simulation and Costola et al. [34] applied airflow network analysis to building energy simulations. Further, Muehleisen and Patrizi [35] developed equation (M\&P equation) for coefficient of pressure in case of small building models.

Nowadays, Machine Learning Algorithms (MLAs) are used extensively as alternative approaches to predicting flow properties in areas of aerodynamics. Recently, MLAs such as Multivariate Adaptive Regression Splines (MARS), Group Method of Data Handling (GMDH), Support Vector Machines (SVM), Genetic Algorithm (GA), Gene-Expression Programming (GEP), Model Tree (MT), Gaussian Process Regression (GPR), Relevance Vector Machine (RVM), and K-Nearest Neighbors (KNN) [36-47] have been successfully adopted to solve a variety of problems relating to water resources as well as hydraulic and hydrological engineering fields.

Samui et al. [48] compared MARS methodology with Artificial Neural Network (ANN) and Finite Element Method (FEM) models and found that the MARS achieved the best outcomes in terms of uplift capacity of suction caisson. Samui and Kurup [49] used MARS and Least Square Support-Vector Machine (LSSVM) to predict the consolidation ratio of clay deposits. Samui [50] predicted the elastic modulus of rock by using MARS and demonstrated the higher performance of MARS model than ANN. Cheng and Cao [51] developed EMARS to predict the energy performance of buildings. Koc and Bozdogan [52] introduced a criterion called information-theoretic measure of complexity (ICOMP) for model selection in MARS to be in agreement with the data and the model complexity and then, they found the ICOMP as the simplest model that could balance the overfitting and underfitting for the MARS model. Zhang and Goh [53] used MARS as an alternative to neural networks to approximate the relationship between the inputs and dependent response and to mathematically interpret the relationship among various parameters for quantifying the 


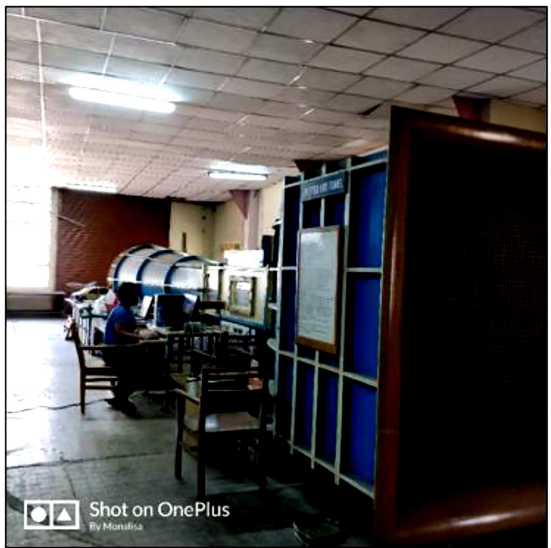

(a)

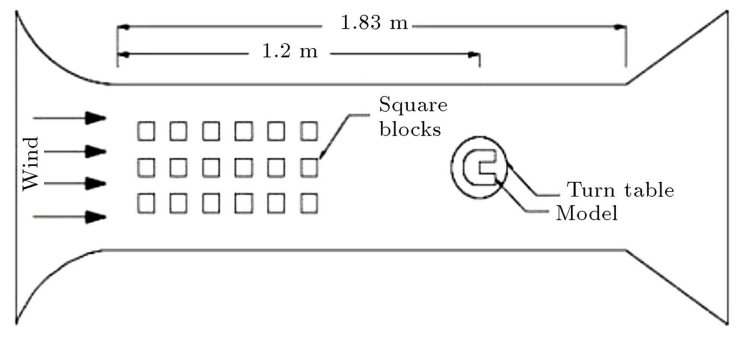

(b)

Figure 1. (a) Sub-Sonic wind tunnel (IIT Kharagpur, India). (b) Schematic diagram for experimental setup of the wind tunnel.

prediction of maximum compressive stresses, maximum tensile stresses, and blow per foot to measure the strength of a pile. Mukhopadhyay [54] explained the methodology by applying MARS to identify damage localization as well as quantification in structures with different damage intensities. Bhattacharya et al. [55] implemented the Functional Network (FN) and MARS models to predict the uplift capacity of suction caisson in clay. The authors found the FN and MARS models to be more efficient to predict the load capacity of clay than other machine learning techniques by various statistical measures. Mirabbasi et al. [56] investigated the performance of the M5Tree model, MARS, least square support vector regression, gene expressing programming, and ANNs methods for estimating the monthly long-term rainfall. Goh et al. [57] also applied the MARS approach to establishing relationships between the maximum surface settlement and the major influencing factors including the operation parameters, cover depth, and ground conditions. Zhang et al. [58] studied the deflection of wall caused by deep braced excavations and applied MARS approach to estimate the possible depth at which maximum lateral deformation occurred. The authors included the 30 data case histories for studying the braced excavation in medium-stiff and soft clays.

\section{Experimental setup}

Experiments were carried out in an open circuit subsonic wind tunnel in the aerodynamic laboratory of the Department of Aerospace Engineering, Indian Institute of Technology Kharagpur, India. The wind speed was kept constant at $12.9 \mathrm{~m} / \mathrm{s}$. The wind tunnel with a bottom surface consisting of a plywood test section was $1.83 \mathrm{~m}$ long with cross-sectional dimensions of $0.61 \mathrm{~m}$ in width and $0.61 \mathrm{~m}$ in depth. Building models were placed within the boundary layer zone, centrally in the test section at a distance of $1.2 \mathrm{~m}$ from the beginning

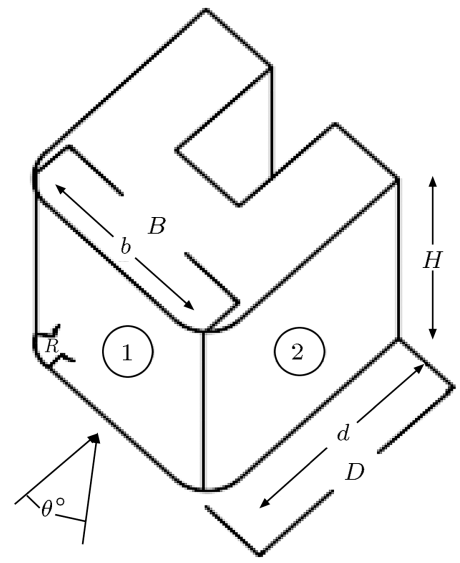

Figure 2. Geometry of C-shaped model defining the surfaces, model dimensions, and angle of incidence.

of the test section. To ascertain models within the boundary layer zone, the roughness elements were placed on the upstream side of the model. For this, wooden cubic blocks of $25 \mathrm{~mm}$ size and clear spacing of $50 \mathrm{~mm}$ in all directions were fixed on $4 \mathrm{~mm}$ thick plywood sheet. Photocopy of a sub-sonic wind tunnel with a schematic illustration is shown in Figure 1.

All the experimental building models were made of transparent Perspex sheet of $3 \mathrm{~mm}$ thickness. Details of the thirteen $\mathrm{C}$-shaped models marked by $\mathrm{C}-1, \mathrm{C}$ $2, \mathrm{C}-3$, and $\mathrm{C}-4$ of varying curvatures, C-5, C-6, and C-7 of varying frontal ratios, and C-8, C-9, C-10, C$11, \mathrm{C}-12$, and $\mathrm{C}-13$ of varying side and height ratio configurations are shown in Figure 2 and Table 1 . The models were fitted with 90 to 120 numbers of pressure tapping points in 4-5 rows and $3-5$ columns on the surfaces. The pressure tapping points were kept at less spacing near the wall boundaries to tap the sharp pressure variation due to flow separation and at larger spacing in the middle of the surfaces.

Free stream velocity during the experiment was measured using Pitot tube. The pressure tapping 
Table 1. Detailed geometry of different C-shaped models.

\begin{tabular}{cccccccc}
\hline Serial no. & $\begin{array}{c}\text { Model } \\
\text { shape }\end{array}$ & $\begin{array}{c}\text { Overall } \\
\text { depth, } \\
\boldsymbol{D}(\mathbf{m m})\end{array}$ & $\begin{array}{c}\text { Overall } \\
\text { breadth, } \\
\boldsymbol{B}(\mathbf{m m})\end{array}$ & $\begin{array}{c}\text { Depth, } \\
\boldsymbol{d}(\mathbf{m m})\end{array}$ & $\begin{array}{c}\text { Breadth, } \\
\boldsymbol{b}(\mathbf{m m})\end{array}$ & $\begin{array}{c}\text { Height, } \\
\boldsymbol{H}(\mathbf{m m})\end{array}$ & $\begin{array}{c}\text { Radius of } \\
\text { curvat ure, } \\
\boldsymbol{R}(\mathbf{m m})\end{array}$ \\
\hline 1 & C-1 & 120 & 120 & 100 & 80 & 80 & 20 \\
2 & C-2 & 120 & 120 & 90 & 60 & 80 & 30 \\
3 & C-3 & 120 & 120 & 80 & 50 & 80 & 40 \\
4 & C-4 & 120 & 120 & 70 & 40 & 80 & 50 \\
5 & C-5 & 110 & 120 & 80 & 60 & 80 & 30 \\
6 & C-6 & 100 & 120 & 70 & 60 & 80 & 30 \\
7 & C-7 & 90 & 120 & 60 & 60 & 80 & 30 \\
8 & C-8 & 120 & 110 & 90 & 50 & 80 & 30 \\
9 & C-9 & 120 & 100 & 90 & 40 & 80 & 30 \\
10 & C-10 & 120 & 90 & 90 & 30 & 80 & 30 \\
11 & C-11 & 120 & 120 & 90 & 60 & 70 & 30 \\
12 & C-12 & 120 & 120 & 90 & 60 & 60 & 30 \\
13 & C-13 & 120 & 120 & 90 & 60 & 50 & 30 \\
\hline
\end{tabular}

points were kept at less spacing near the wall boundaries to tap the sharp pressure variation due to flow separation and at larger spacing in the middle of the surfaces. The free ends of tubes were connected to Digital Sensor Array (DSA) to record the fluctuating wind pressures at the corresponding tapping points. All data were measured by a DSA scan valve corporation, Model DSA 3217/16 pox, USA. This DSA device is set to give an average pressure of 5 seconds in duration. At the same time, for greater accuracy, a pressure measurement at each tapping point was repeated for three times and the mean of three pressure data sets was obtained. The pressure coefficient $\overline{C_{p}}$ for each tapping point was calculated by putting the pressure data in equation of pressure coefficient.

\section{Methods for the prediction of $\overline{C_{p}}$ on the surfaces of the building model}

Predictive modeling is the process of creating, testing, and validating the probability to forecast outcomes. The model involves two types of parameters: dependent and independent. Following the collection of data on relevant parameters, a number of statistical tools and analytical techniques were used to develop the forecasting model. The earlier researchers have also presented analytical models to predict the surface mean pressure coefficient $\left(\overline{C_{p}}\right)$. Some of the main models are mentioned below.

\subsection{Swami and Chandra (S\&C) equation}

The S\&C equation [29] is proposed for calculating the mean pressure coefficient on the surface of low-rise buildings given below:

$$
\begin{aligned}
\overline{C_{p}}(\theta, D / B)= & \overline{C_{p}}\left(0^{\circ}\right) \ln [1.248-0.703 \sin (\theta / 2) \\
& -1.175 \sin ^{2}(\theta)+0.131 \sin ^{3}(2 G \theta) \\
& +0.769 \cos (\theta / 2) !+0.07 G^{2} \sin ^{2}(\theta / 2) \\
& \left.+0.717 \cos ^{2}(\theta / 2)\right]
\end{aligned}
$$

where $\theta$ indicates the angle of wind incidence on the surface, $G$ is the logarithmic of the ratio side face described as $\ln (D / B)$, and $\overline{C_{p}}\left(0^{\circ}\right)$ and $\overline{C_{p}}$ are the values at $0^{\circ}$ angles of incidence.

\subsection{Muehleisen and Patrizi (M\&P) equation}

The M\&P equation [35] was developed to calculate the mean coefficient of pressure on the wall of a low-rise building with different angles of incidence, $\theta$, and the side ratio $D / B$ given as follows:

$$
\begin{gathered}
\overline{C_{p}}(\theta, D / B)=\frac{a_{o}+a_{1} G+a_{2} \theta+a_{3} \theta^{2}+a_{4} G \theta}{1+b_{1} G+b_{2} \theta+b_{3} \theta^{2}+b_{4} G \theta}, \\
G=\ln (D / B),
\end{gathered}
$$

where $a_{i}$ and $b_{i}$ are the adjustable factors with different values described below, $\theta$ is the angle of incidence, and $G$ is the logarithmic of the ratio side face described as $\ln (D / B)$. The values of $a_{i}$ and $b_{i}$ are given as follows:

$$
\begin{array}{ll}
a_{o}=6.12 \times 10^{-1}, & a_{1}=-1.78 \times 10^{-1}, \\
a_{2}=-1.15 \times 10^{-2}, & a_{3}=3.28 \times 10^{-5}, \\
a_{4}=1.67 \times 10^{-3}, & \\
b_{1}=-3.12 \times 10^{-1}, & b_{2}=-1.59 \times 10^{-2},
\end{array}
$$




$$
b_{3}=9.82 \times 10^{-5}, \quad b_{4}=2.15 \times 10^{-3} .
$$

\subsection{Authors' approaches for new model}

The most popular database method from the machine learning field is the MARS and was adopted here to obtain a model for the prediction of surface mean $\overline{C_{p}}$ on the faces of C-shaped models. The data were used in the present work to formulate and simulate the method, as shown in Table 1.

The surface mean pressure coefficient $\left(\overline{C_{p}}\right)$ is a function of overall side ratio $(D / B),(d / b)$, height ratio $(H / D)$, and curvature, and wind angle of incidence $(\theta)$ of the building model. Here, in the MARS modeling, the normalized value of independent variables was taken as inputs. Then, the output of the model was the normalized value of mean pressure coefficient from which actual values are obtained. The $75 \%$ of the data of the mentioned dataset were designated for training and another $25 \%$ of data for testing the proposed model. The data were normalized between 0 and 1 . Normalization occurred using the following equation:

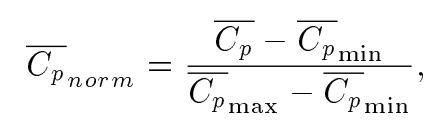

where $\overline{C_{p}}$ is any finite data, $\overline{C_{p \min }}$ the minimum value of the data, $\overline{C_{p \max }}$ the maximum value of the data, and $\bar{C}_{\text {pnorm }}$ the normalized value of the data.

\subsubsection{Multivariate Adaptive Regression Spline (MARS)}

The most popular database method from the machine learning field is the MARS and it was adopted here to obtain a model for the prediction of $\overline{C_{p}}$ on building models. The MARS is a type of the non-parametric regression model first introduced by Friedman [59]. It also divided the data into several splines at the corresponding interval in which each spline split the predictors into subgroups and knots for non-linear relationships by Friedman and Roosen [60]. According to Leathwick et al. [61], MARS splits the input variables into piecewise linear segments to make a non-linear association between dependent (output) and independent (input) variables. The formulation of MARS is written in the following form:

$$
y=c_{0}+\sum_{i=1}^{N} c_{i} \prod_{j=1}^{K_{i}} b_{j i}\left(x_{v(j, i)}\right),
$$

where $y$ is the dependent output variable, $c_{0}$ the constant term, $c_{i}$ the coefficient vector of the nonconstant basis functions, $B_{j i}\left(x_{v(j, i)}\right)$ the truncated power basis function, and $x_{v(j, i)}$ the index of the independent input variable of the $i$ th term and the $j$ th product, and $K_{i}$ is the order of interaction limit. The definition of spline $b_{j i}$ is shown as follows:

$$
\begin{aligned}
& b_{j i}(x)=\left(x-t_{j i}\right)_{+}^{q}= \begin{cases}\left(x-t_{j i}\right)^{q}, & x<t_{j i} \\
0, & \text { otherwise }\end{cases} \\
& b_{j i+1}(x)=\left(t_{j i}-x\right)_{+}^{q}= \begin{cases}\left(t_{j i}-x\right)^{q}, & x<t_{j i} \\
0, & \text { otherwise }\end{cases}
\end{aligned}
$$

where $t_{j i}$ is the loop of the spline. The MARS model works through two steps: a forward process followed by a backward process. The truncated power basis functions are chosen based on the Residual Sumof-Squares (RSSs) and Generalized Cross-Validation (GCV) principles (Craven and Wahba) [62]. The ineffective basis functions are considered unused for the prediction of the model. RSSs are measured in the training process through which the model parameters are compared using Eq. (7):

$$
R S S=\sum_{i=1}^{N}\left[y_{i}-f\left(x_{i}\right)\right]^{2} .
$$

To compare the performance of the predictors in the backward pass, GCV is used. The lower values of GCV show a better subset of predictors. The GCV shows precision against model complexity. The GCV evaluation is defined as follows:

$$
G C V=\frac{\frac{1}{N} \sum_{i=1}^{N}\left[y_{i}-f\left(x_{i}\right)\right]^{2}}{\left[1-\frac{C(B)}{N}\right]^{2}},
$$

where $N$ is the number of data and $C(B)$ is the penalty function, which increases with the number of basic functions and is defined as follows:

$$
C(B)=B+d\left(\frac{B-1}{2}\right),
$$

where $B$ is the number of basis terms and $d$ the penalty term in the respective functions provided by Friedman [59]. It can also be considered as a smoothing parameter.

\subsubsection{Development of model for surface 1}

In MARS model, 17 basis functions are used initially in the forwarding step, out of which five basic functions are deleted in the backward step process to obtain an optimum model for the prediction of $\overline{C_{p}}$. Thus, the final MARS model is restricted to 12 numbers of basic functions. Here, four input parameters are used for the development of MARS model to predict $\overline{C_{p}}$ as the output parameter. RSS and GCV criteria are also performed to know the importance of the predictors using Eqs. (7) and (8), respectively, which are given in Table 2. The ranking of parameters as per RSS and GCV criteria is as follows: radian $(\theta)(1), d / b(2), H / D$ $(3)$, and $R / D(4)$. 
Table 2. Generalized Gross-Validation (GCV) and Residual Sum-of-Square (RSS) criteria analysis in Multivariate Adaptive Regression Spline (MARS) model.

\begin{tabular}{ccc}
\hline Parameters & GCV & RSS \\
\hline radian $(\theta)$ & 100 & 100 \\
$d / b$ & 27.1 & 29.3 \\
$H / D$ & 12.4 & 15 \\
$R / D$ & 7.2 & 11.5 \\
\hline
\end{tabular}

The surface mean pressure coefficient $\left(\overline{C_{p}}\right)$ is quantified through linear arrangement of the constant -0.39 for surface 1 . The basis functions, shown in Table 3, super imposed with their respective coefficients were achieved by the models.

Finally, the optimal model aimed at predicting $\overline{C_{p}}$ on surface 1 is presented as follows:

$$
\overline{C_{p}}=-0.39+\sum_{i=1}^{12} c_{i} B_{i}(x),
$$

where $\overline{C_{p}}$ is the average pressure coefficient at a face, $B_{i}(x)$ the basic function, and $c_{i}$ the coefficient.

\subsubsection{Development of model for surface 2}

For the second surface, 12 basis functions were used initially in the forwarding step out of which 8 basis functions were deleted through the backward step process to obtain an optimum model to predict the value of $\overline{C_{p}}$. Therefore, the final MARS model was restricted to four basis functions. Here, three input parameters for the development of MARS model were taken to predict the value of $\overline{C_{p}}$ as the output parameter. The surface mean pressure coefficient $\left(\overline{C_{p}}\right)$ was quantified through
Table 4. Basis functions $B_{i}(x)$ and coefficients $\left(c_{i}\right)$ used for obtaining Multivariate Adaptive Regression Spline (MARS) model.

\begin{tabular}{cc}
\hline Basis Function, $\boldsymbol{B}_{\boldsymbol{i}}(\boldsymbol{x})$ & $\boldsymbol{c}_{\boldsymbol{i}}$ \\
\hline$B_{1}(x)=\max (0,(R / D)-0.27)$ & -2.1 \\
$B_{2}(x)=\max (0,1-\operatorname{radian}(\theta))$ & -1.5 \\
$B_{3}(x)=\max (0$, radian $(\theta)-1.6)$ & -0.72 \\
$B_{4}(x)=(d / D) \times(R / D) \times \max ($ radian $(\theta)-1)$ & -0.29 \\
\hline
\end{tabular}

linear arrangement of the constant 0.8 for the second surface.

Finally, the following optimal model was produced for prediction of $\overline{C_{p}}$ value on surface 2 :

$$
\overline{C_{p}}=0.8+\sum_{i=1}^{4} c_{i} B_{i}(x) .
$$

The values of $B_{i}(x)$ with their respective coefficients $\left(c_{i}\right)$ are shown in Table 4.

\section{Model performance assessment}

It is important to estimate the sensitivity of each parameter of the proposed model to its significance. The sensitivity analysis is used to evaluate the independent parameters proposed by Barati et al. [63], Barati [64], and Akhbari and Barati [65] for flood routing study, and they recommended analyzing the influence of each parameter. Similarly, Gandomi et al. [66] studied the effect of multiple parameters on a single result. The percentage of sensitivity $\left(S_{i}\right)$ for the independent parameters was established through the following expressions:

Table 3. Basis functions $B_{i}(x)$ and coefficients $\left(c_{i}\right)$ used for obtaining Multivariate Adaptive Regression Spline (MARS) model for surface 1 .

\begin{tabular}{cc}
\hline Basis Function, $\boldsymbol{B}_{\boldsymbol{i}}(\boldsymbol{x})$ & $\boldsymbol{c}_{\boldsymbol{i}}$ \\
\hline$B_{1}(x)=\max (0,2-(d / b))$ & 0.39 \\
$B_{2}(x)=\max (0,(R / D)-0.3)$ & -1.4 \\
$B_{3}(x)=\max (0$, radian $(\theta)-0.52)$ & -0.93 \\
$B_{4}(x)=\max (0$, radian $(\theta)-1.05)$ & 0.65 \\
$B_{5}(x)=\max (0,1.57-$ radian $(\theta))$ & 1.3 \\
$B_{6}(x)=\max (0$, radian $(\theta)-1.57)$ & 0.65 \\
$B_{7}(x)=(R / D) \times \max (0,1.57-$ radian $(\theta))$ & -1.5 \\
$B_{8}(x)=\max (0,2-(d / b)) \times \max (0,(R / D)-0.25)$ & 1.8 \\
$B_{9}(x)=\max (0,2-(d / b)) \times \max (0$, radian $(\theta)-1.57)$ & -0.24 \\
$B_{10}(x)=\max (0,2-(d / b)) \times \max (0,1.57-$ radian $(\theta))$ & -0.3 \\
$B_{11}(x)=\max (0,0.67-(H / D)) \times \max (0$, radian $(\theta)-0.52)$ & 0.22 \\
$B_{12}(x)=\max (0,0.3-(R / D)) \times \max (0,1.047-$ radian $(\theta))$ & -3.1 \\
\hline
\end{tabular}


Table 5. Sensitivity analysis of different parameters.

\begin{tabular}{|c|c|c|c|c|}
\hline Parameters & $d / b$ & $H / D$ & $R / D$ & $\theta$ \\
\hline Sensitivity (\%) & 13.55 & 46.68 & 2.02 & 37.59 \\
\hline$N_{i}=f_{\max }\left(x_{i}\right)-$ & $\operatorname{in}\left(x_{i}\right)$ & & & \\
\hline$S_{i}(\%)=\frac{N_{i}}{\sum_{i=1}^{n} N}$ & $\times 100$ & & & \\
\hline
\end{tabular}

where $f_{\max }\left(x_{i}\right)$ and $f_{\min }\left(x_{i}\right)$ are the corresponding maximum and minimum values of predicted result over the $i$ th independent factor by considering the mean values of former factors. $S_{i}$ denotes the percentage of sensitivity, as given in Table 5 , for individual factors.

The testing of the model performance is a vital task following the development of a model, where a comparison between the observed $\left(C p_{o i}\right)$ and predicted $\left(C p_{p i}\right)$ values of $\overline{C_{p}}$ is made. The interpretation of the MARS model is demonstrated through their standard statistical error calculations such as coefficient of correlation $\left(R^{2}\right)$, Root-Mean-Square-Error (RMSE), Mean Absolute Error (MAE), and the Mean Absolute Percentage Error (MAPE). The values of $R^{2}$, RMSE, MAE, and MAPE were determined by Gandomi et al. [66] and Ebtehaj et al. [67] through the following equations:

$$
\begin{gathered}
R^{2}=\frac{\sum_{i=1}^{N}\left(C p_{o i}-\overline{C p_{o}}\right)^{2}\left(C p_{p i}-\overline{C p_{p}}\right)^{2}}{\sum_{i=1}^{N}\left(C p_{o i}-\overline{C p_{o}}\right)^{2} \sum_{i=1}^{N}\left(C p_{p i}-\overline{C p_{p}}\right)^{2}}, \\
M A E=\frac{\sum_{i=1}^{N}\left|C p_{o i}-C p_{p i}\right|}{N}, \\
R M S E=\sqrt{\frac{\sum_{i=1}^{N}\left(C p_{o i}-C p_{p i}\right)^{2}}{N}}, \\
M A P E=\frac{\sum_{i=1}^{N}\left(\frac{\left|C p_{o i}-C p_{p i}\right|}{C p_{o i}} \times 100\right)}{N},
\end{gathered}
$$

where $\left(C p_{o i}\right)$ and $\left(C p_{p i}\right)$ are the observed and the predicted values of $\overline{C_{p}}$, respectively, $\overline{C_{p_{o}}}$ the mean of the observed $\overline{C_{p}}$ values, $\overline{C p_{p}}$ the mean of the predicted $\overline{C_{p}}$, and $N$ the number of data samples.

The closure is the value of $R^{2}$ set to 1 and it shows a favorable correlation between the observed and predicted values of various models. MAE measures the closeness between the predicted and observed values, while RMSE shows the deviation of the predicted value from the observed value. MAE and RMSE have a unit similar to the dependent input value, i.e., a lower value of predictive variables depicts a better prediction model. MAE and RMSE is converted to unit less as NMAE and NRMSE for anonymous consideration of the model for various types of dataset. Therefore, MAE and RMSE denote percentages of the difference between maximum and minimum predicted values, which are the normalized values. The normalized values of RMSE and MAE are expressed as Normalized Root Mean Square Error (NRMSE) and Normalized Mean Absolute Error (NMAE), respectively, which are presented in the following:

$$
\begin{gathered}
N M A E=\frac{M A E}{\max \left(\overline{C_{p}}\right)-\min \left(\overline{C_{p}}\right)}, \\
N R M S E=\frac{R M S E}{\max \left(\overline{C_{p}}\right)-\min \left(\overline{C_{p}}\right)} .
\end{gathered}
$$

\section{Results and discussion}

\subsection{Windward surface (surface 1) of $C$ - shaped model buildings}

Following the development of the model (Eq. (10)), an attempt is made to test the strength. A comparison (Figure 3 ) is made between the predicted values of $\overline{C_{p}}$ using the developed model (Eq. (10)) and the corresponding observed values of $\overline{C_{p}}$.

It is clearly seen from the above figure that the predicted values of $\overline{C_{p}}$ are in good agreement with the corresponding observed values.

The authors also compared the predicted results with the values obtained using different equations (Eqs. (1) and (2)) on the surfaces of the building models. The comparisons of the experimental values of $\overline{C_{p}}$ (with the angle of incidence) and those obtained from different models including the proposed model, are shown in Figures 4 to 7 . Here, the authors attempted to show the curvature effect on $\overline{C_{p}}$ by

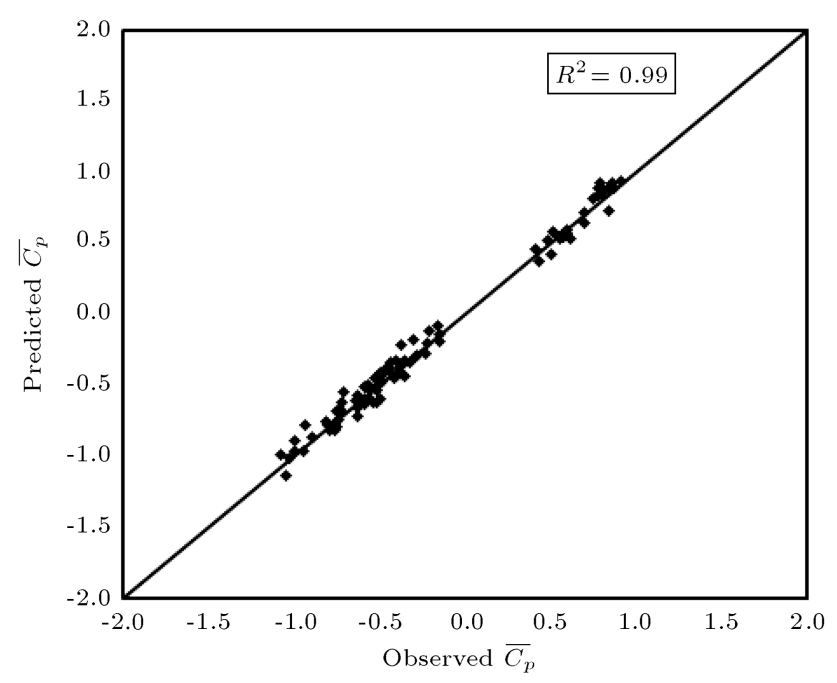

Figure 3. Comparison between observed and predicted surface mean pressure coefficient $\left(\overline{C_{p}}\right)$ values for surface 1 . 


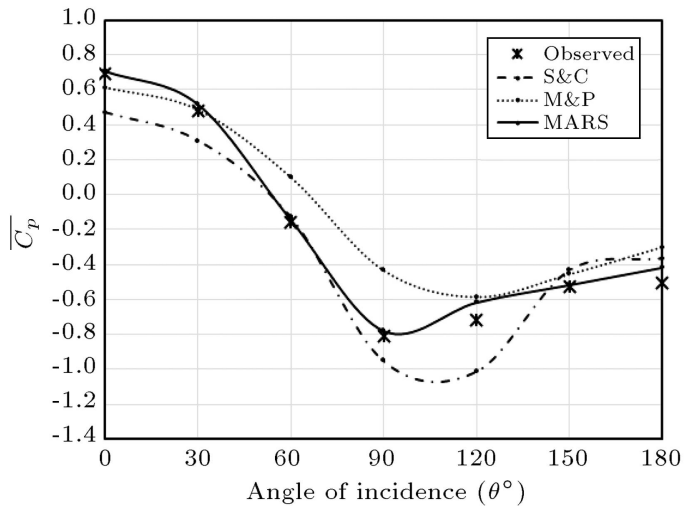

(a) $d / b=1.25, R=20$

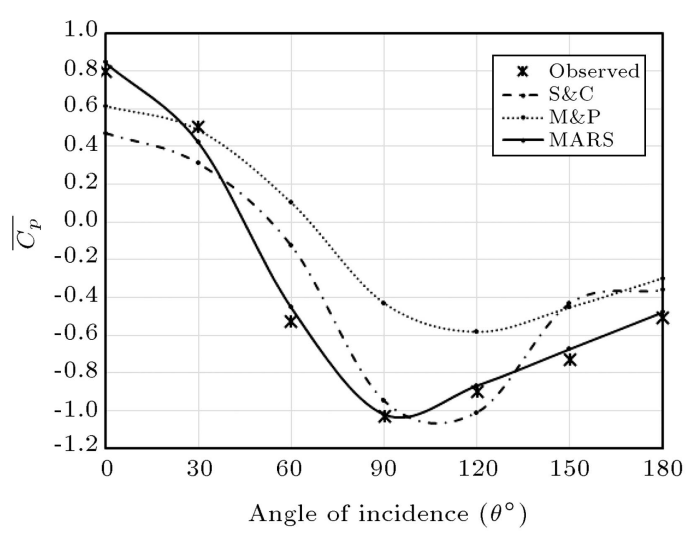

(c) $d / b=2, R=40$

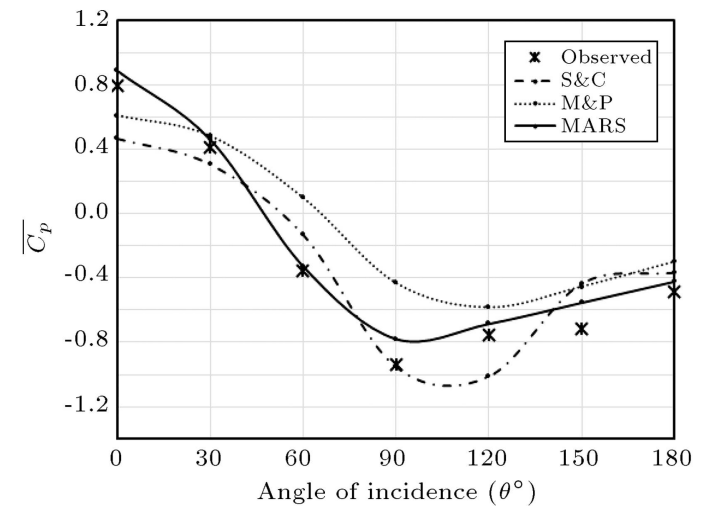

(b) $d / b=1.5, R=30$

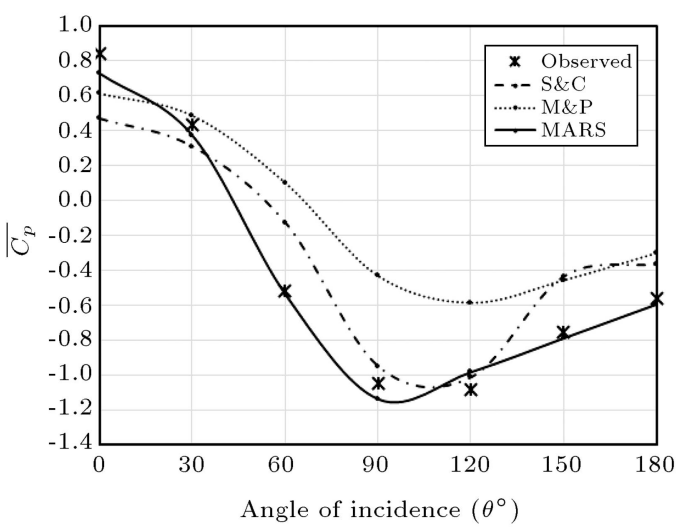

(d) $d / b=3.5, R=50$

Figure 4. Comparison between observed $\overline{C_{p}}$ data and predicted values of different curvatures.

changing side ratios. In Case $\mathrm{I}$, the variations in $\overline{C_{p}}$ with the angle of incidence for different curvatures are shown (Figure $4(\mathrm{a})$ to $(\mathrm{d})$ ) by maintaining the side ratio $(D / B)$ as 1 and height ratio $(H / D)$ as 0.67 . In Case II, height ratio $(H / D)$ and radius of curvature $(R)$ are kept constant and variation in $\overline{C_{p}}$ with the angle of incidence $\theta$ at different side ratios, i.e. $D / B$ and $d / b$, is shown in Figure 5(a) to (d). In Case III, height ratio $(H / D)$ and radius of curvature $(R)$ are kept constant and variations in $\overline{C_{p}}$ with the angle of incidence $\theta$ at different frontal ratios, i.e., $D / B$ and $d / b$, are shown in Figure $6(\mathrm{a})$ to $(\mathrm{d})$. In Case IV, the variation in $\overline{C_{p}}$ with the angle of incidence is shown at different height ratios (Figure $7(\mathrm{a})$ to $(\mathrm{d})$ ) by maintaining the side ratio $(D / B, d / b)$ and radius of curvature $(R)$ constant as 1 , 1.5 , and 0.5 , respectively.

Case I: Variation of surface mean pressure coefficient $\left(\overline{C_{p}}\right)$ with the angle of incidence $(\theta)$ for different curvatures. Figure $4(\mathrm{a})$ to $(\mathrm{d})$ show the values $\overline{C_{p}}$ of surface 1 (a front face) of the model as a function of the wind angle of incidence $(\theta)$. It can be seen that the prediction obtained by the MARS model and the corresponding observed data are in good agreement with the $\mathrm{S} \& \mathrm{C}$ equation data in the entire range of incidence angles. However, results of the M\&P equation prediction are in close agreement with the MARS and observed data in the lower range of wind incidence angles, i.e., $0^{\circ}$ to $90^{\circ}$ and the higher range of $120^{\circ}$ to $180^{\circ}$. In the middle range of wind incidence angles $\left(90^{\circ}\right.$ to $\left.120^{\circ}\right), \mathrm{M} \& \mathrm{P}$ equation data deviate from those of MARS and S\&C data. M\&P performs usually better than S\&C, as stated by Muehleisen and Patrizi [35]. The comparison between the data obtained by MARS model and those by other two models authenticates the chosen MARS model and the effectiveness to forecast $\overline{C_{p}}$ for the entire series of wind incidence angles;

Case II: Variation of surface mean pressure coefficient $\left(\overline{C_{p}}\right)$ with the angle of incidence $(\theta)$ at different side ratios. Figure $5(\mathrm{a})$ to $(\mathrm{d})$ shows $\overline{C_{p}}$ on surface 1 at different side ratios $D / B$ and $d / b$ as a function of the wind angle of incidence $\theta$. Here, MARS unveils the correctness of the calculated data for any $D / B$ and $\theta$ and it facilitates accurate prediction of the calculated data. MARS prediction is closer to the observed data in all the cases. The predictions made by MARS model and the corresponding observed data are in close agreement with the S\&C equation data in the entire range of incidence angles. As in Case I, M\&P equation predictions are in close 


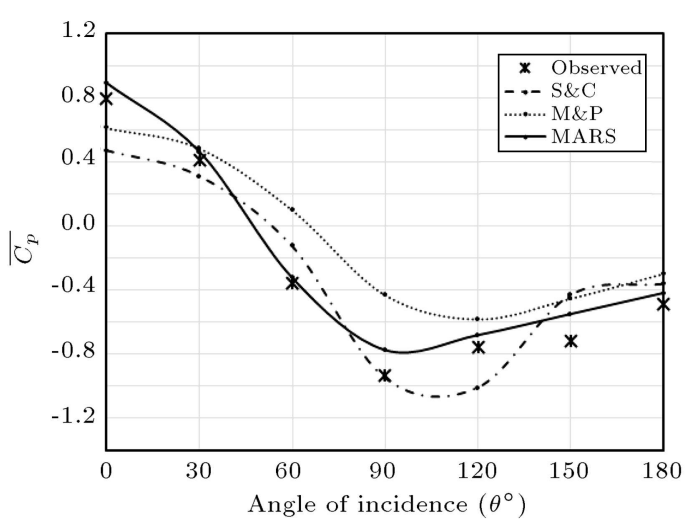

(a) $D / B=1, d / b=1.5$

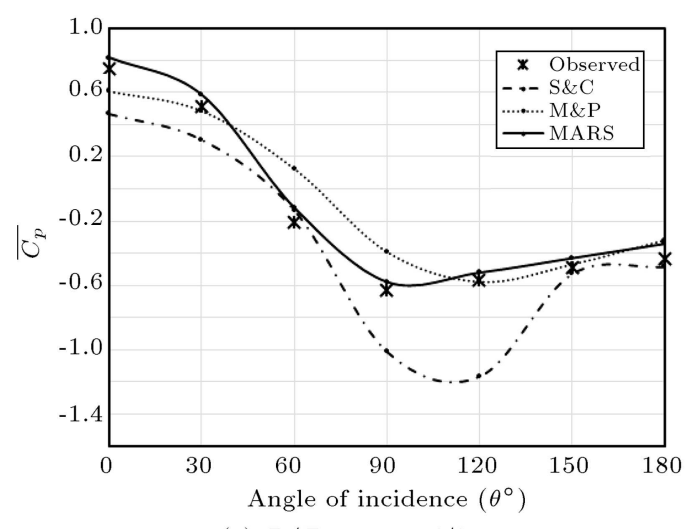

(c) $D / B=0.83, d / b=1.16$

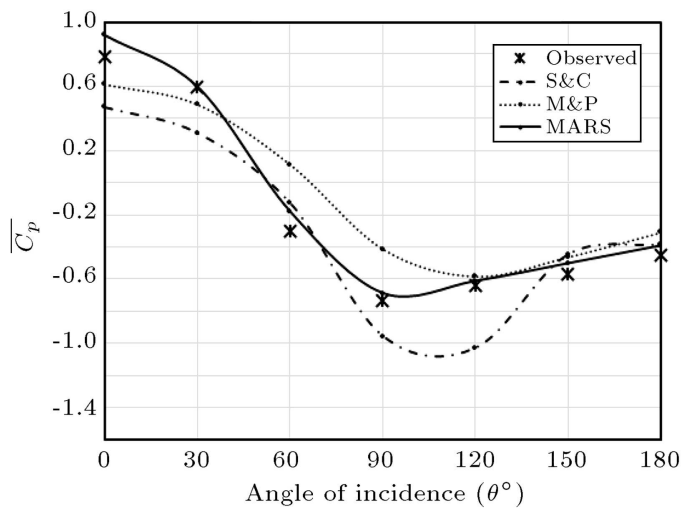

(b) $D / B=0.92, d / b=1.33$

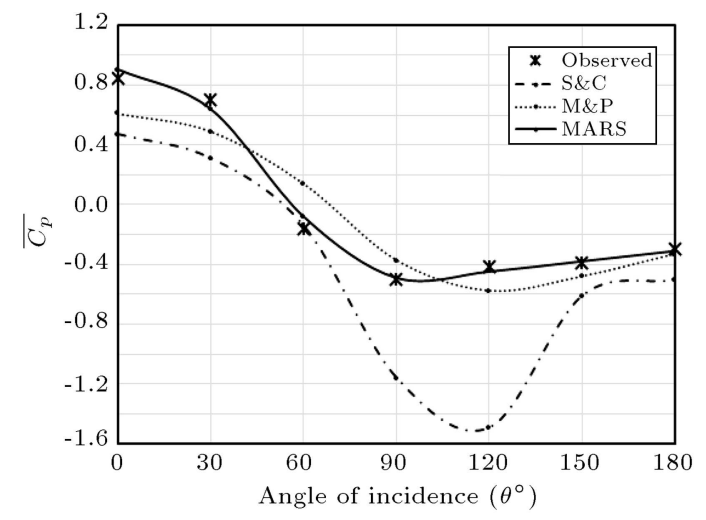

(d) $D / B=0.75, d / b=1$

Figure 5. Comparison between observed $\overline{C_{p}}$ data and predicted values at different side ratios.

agreement with others only in the lower range of wind incidence angles, i.e., $0^{\circ}$ to $90^{\circ}$ and the higher range of $120^{\circ}$ to $180^{\circ}$. However, in the middle range of wind incidence angles $\left(90^{\circ}\right.$ to $\left.120^{\circ}\right)$, M\&P equation data deviate from those of MARS and S\&C data;

Case III: Variation of surface mean pressure coefficient $\left(\overline{C_{p}}\right)$ with the angle of incidence $(\theta)$ at different frontal ratios. Figure $6(\mathrm{a})$ to $(\mathrm{d})$ shows $\overline{C_{p}}$ on surface 1 at different frontal ratios of $D / B$ and $d / b$ as a function of the wind angle of incidence $(\theta)$. Here, MARS ensures a good correlation of the measured data for any $D / B$ and $\theta$ and finds an accurate prediction of the measured data. MARS prediction is closer to the observed data in all of the cases. The predictions made by MARS model and the corresponding observed data are in close agreement with the $\mathrm{S} \& \mathrm{C}$ equation data in the entire range of incidence angles. As in Case I, M\&P equation predictions are in close agreement with others only in the lower range of wind incidence angles i.e., $0^{\circ}$ to $90^{\circ}$ and the higher range of $120^{\circ}$ to $180^{\circ}$. However, in the middle range of wind incidence angles $\left(90^{\circ}\right.$ to $\left.120^{\circ}\right)$, the data of $\mathrm{M} \& \mathrm{P}$ equation deviate from those of MARS and S\&C;

Case IV: Variation of surface mean pressure coefficient $\overline{C_{p}}$ with the angle of incidence $(\theta)$ at different height ratios. Figures $7(\mathrm{a})$ to $(\mathrm{d})$ show $\overline{C_{p}}$ on surface 1 of the model as a function of the wind incidence angle $\theta$. It can be seen that the predictions of $\overline{C_{p}}$ by the developed MARS model and other two $\mathrm{S} \& \mathrm{C}$ and $\mathrm{M} \& \mathrm{P}$ equations are in good agreement with observed data in the lower range of angles of incidence $\left(0^{\circ}\right.$ to $60^{\circ}$ ) and again beyond $150^{\circ}$. The predictions by $\mathrm{M} \& \mathrm{P}$ model in the middle range of angles of incidence $\left(60^{\circ}\right.$ to $\left.150^{\circ}\right)$ deviate from others. Moreover, the predictions by MARS models are in close agreement with the observed data and $\mathrm{S} \& \mathrm{C}$ predictions in the entire range of angles of incidence.

The sensitivity analysis of each parameter involved is obtained and presented in Table 5.

Table 5 shows that the pressure coefficients are significantly affected by $d / b, H / D, R / D$, and $\theta$. The height ratio $(H / D)$ has the highest influence on pressure coefficient $(46.68 \%)$ followed by the angle $(\theta)$ and side ratio $(d / b)$ of $37.59 \%$ and $13.55 \%$, respectively. The $R / D$ ratio has a sensitivity rate of $2.02 \%$ influencing the capacity of predicting the average pressure coefficient. The $R / D$ ratio has a quite insignificant effect on the average pressure coefficient.

Gandomi et al. [66] carried out error analysis and obtained Coefficient of Determination $\left(R^{2}\right)$, MAE, RMSE, and MAPE. Table 6 shows the error analysis of 


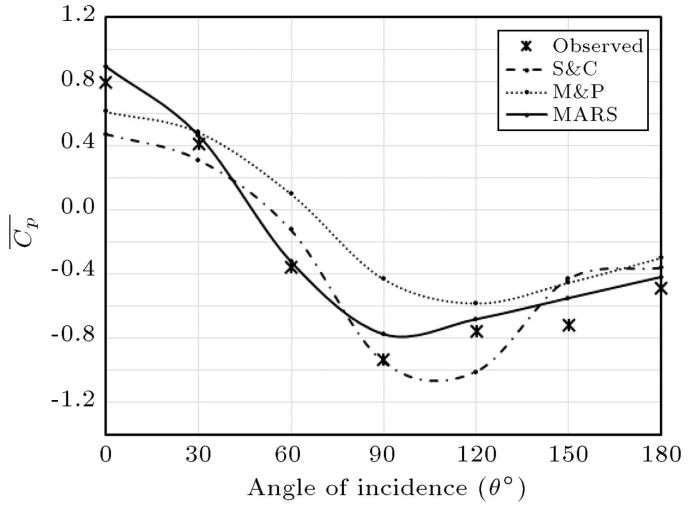

(a) $D / B=1, d / b=1.5$

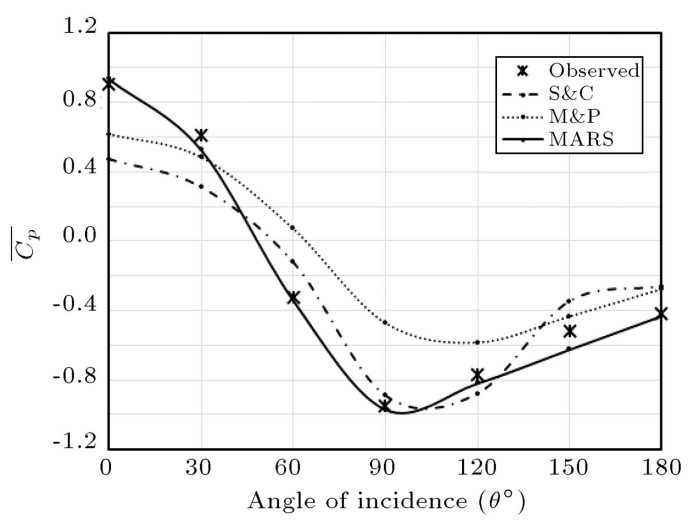

(c) $D / B=1.2, d / b=2.25$

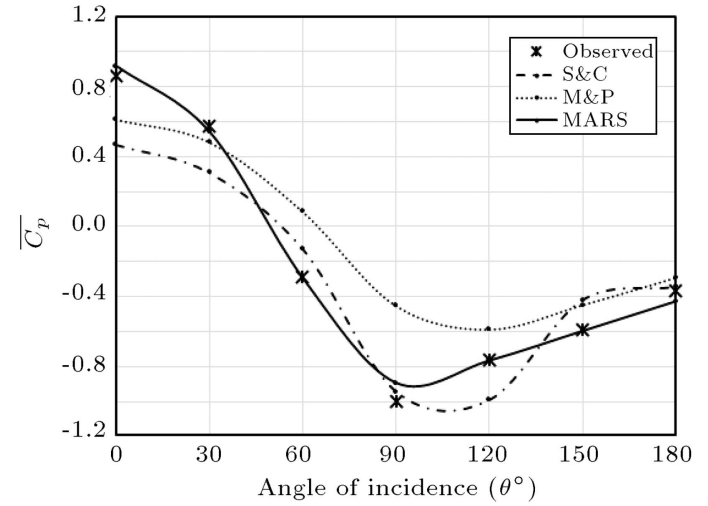

(b) $D / B=1.09, d / b=1.8$

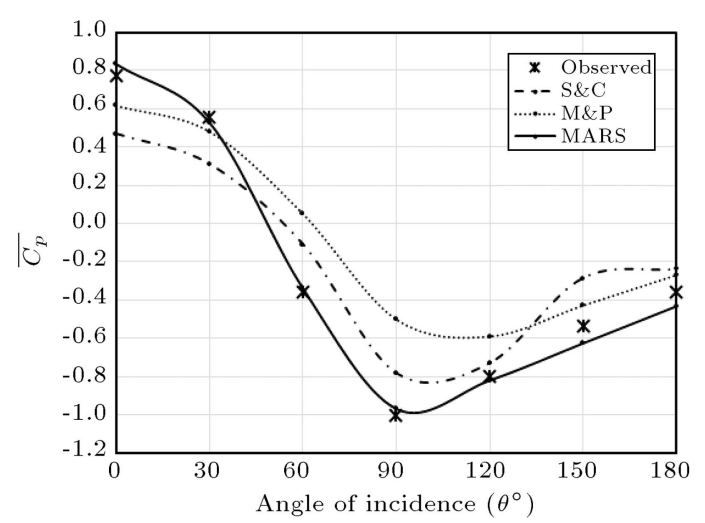

(d) $D / B=1.33, d / b=3$

Figure 6. Comparison between observed $\overline{C_{p}}$ data and predicted values at different frontal ratios.

Table 6. Error analysis of predicted $\overline{C_{p}}$ by Multivariate Adaptive Regression Spline (MARS) against reported models for experimental data.

\begin{tabular}{cccc}
\hline Models & S\&C & M\&P & MARS \\
\hline ME (\%) & -4.80 & -27.22 & -2.61 \\
$R^{2}$ & 0.77 & 0.82 & 0.99 \\
MAE & 0.24 & 0.23 & 0.05 \\
RMSE & 0.31 & 0.29 & 0.06 \\
MAPE (\%) & -21.59 & -32.10 & -5.83 \\
\hline
\end{tabular}

the present experimental dataset with different predictive models. From the above analysis, we can conclude that the MARS model could outperform other models in accurately predicting the coefficient of pressure on the surface of the C-shaped model. Better results of error analysis show the acceptability of the MARS model for the practical application.

For a better understanding, the performances of the models, NMAE in \% and NRMSE in \%, are compared with $\mathrm{S} \& \mathrm{C}$ and $\mathrm{M} \& \mathrm{P}$ equations as given in Figure 8(a) and (b), respectively. The developed MARS model obtains lower values of NMAE and
Table 7. Error analysis of predicted $\overline{C_{p}}$ by Multivariate Adaptive Regression Spline (MARS) model for surface 2.

\begin{tabular}{ccccc}
\hline ME (\%) & $\boldsymbol{R}^{\mathbf{2}}$ & MAE & RMSE & MAPE \\
\hline-0.28 & 0.98 & 0.07 & 0.09 & 35.94 \\
\hline
\end{tabular}

NRMSE for the data concerning the S\&C and M\&P equations.

\subsection{Side surface (surface 2) of C-shaped model buildings}

Another attempt is also taken to predict the values of surface mean pressure coefficient for side surface (surface 2) of C-shaped building models which is provided in Eq. (11). A comparison was made between the predicted values of $\overline{C_{p}}$ using the developed model (Eq. (11)) and the corresponding observed values of $\overline{C_{p}}$. As seen in Figure 9, the forecasted values of $\overline{C_{p}}$ were in good agreement with the corresponding observed ones. The error analysis was also carried out to show the acceptability of the developed model on the side face. Table 7 shows the error analysis of the present experimental dataset with predictive models on the side face.

The comparison between the predicted values of $\overline{C_{p}}$ using the developed MARS model and the corresponding observed one with the angle of incidence 


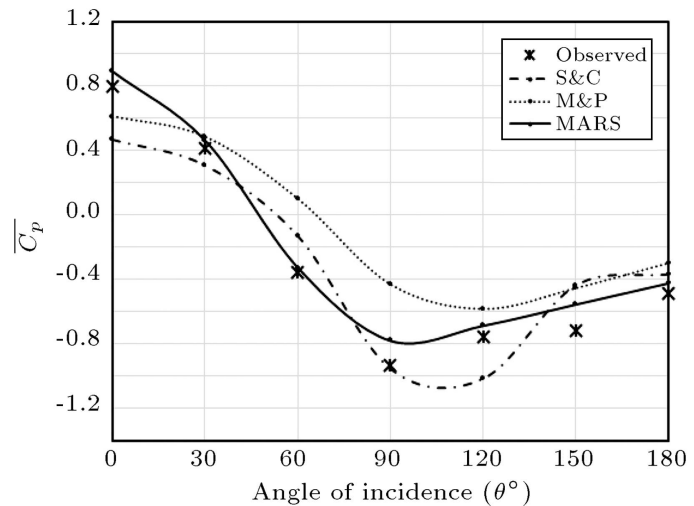

(a) $H / D=0.67$

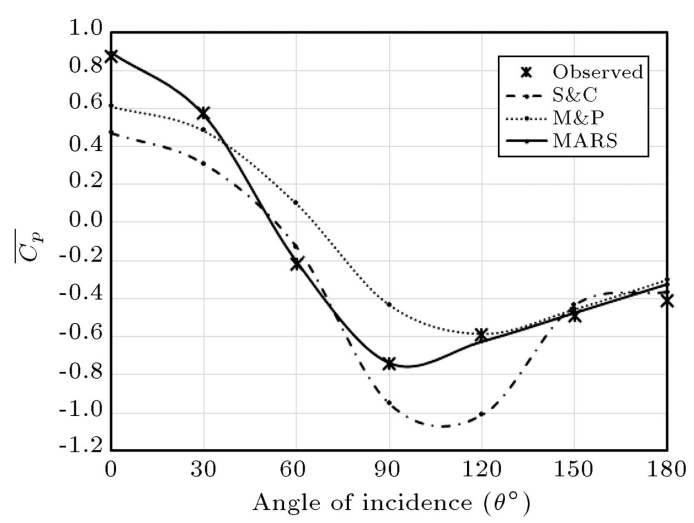

(c) $H / D=0.5$

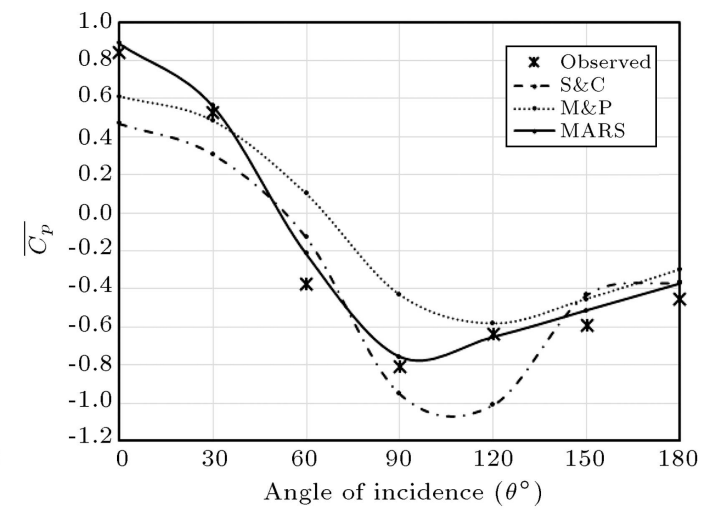

(b) $H / D=0.58$

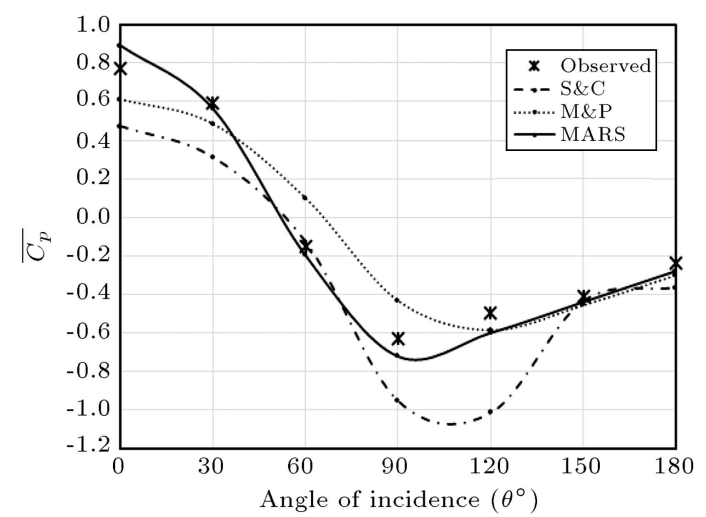

(d) $H / D=0.42$

Figure 7. Comparison between observed $\overline{C_{p}}$ data and predicted values of different height ratio.

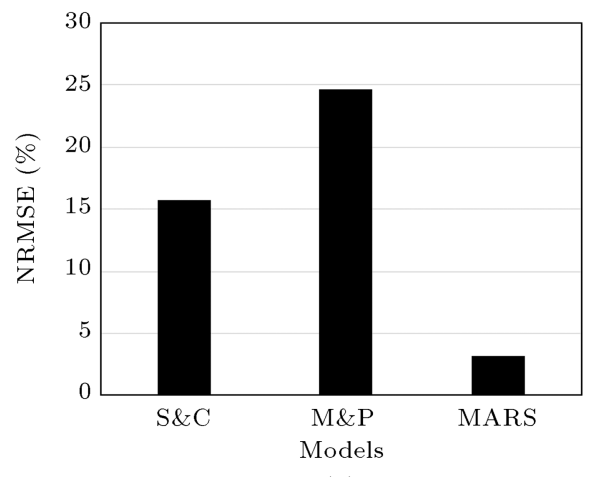

(a)

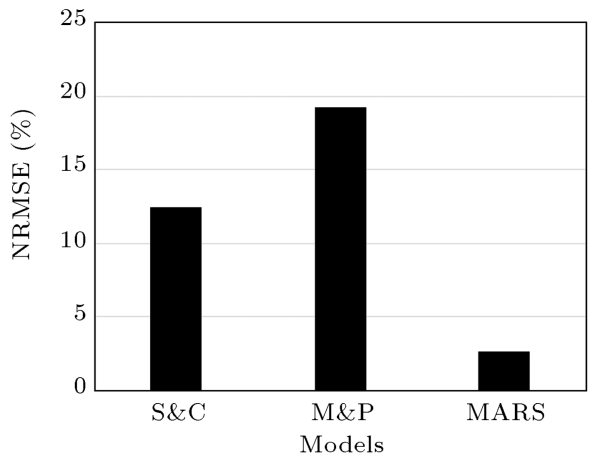

(b)

Figure 8. Comparison between the performance of Multivariate Adaptive Regression Spline (MARS) model and Swami and Chandra $(\mathrm{S} \& \mathrm{C})$ and M\&P equations.

was also made for the varying cases of curvatures, side ratio and frontal ratio $(D / B$ and $d / b)$, and height ratio $H / D$.

Figure $10(\mathrm{a})$ to $(\mathrm{d})$ show the predicted and observed values of $\overline{C_{p}}$ with angles of incidence for different curvatures. Similarly, the predicted and observed values of $\overline{C_{p}}$ with angles of incidence for varying cases of side ratio and frontal ratio $(D / B$ and $d / b)$ as well as height ratio (H/D) are presented in Figures 11(a) to (d), 12(a) to (d), and 13(a) to (d), respectively.

According to the above figures, the predicted values of $\overline{C_{p}}$ are in fairly good agreement with the corresponding observed ones.

\subsection{Validation of the developed model with TPU dataset}

The predictions made by the developed model were compared with the data of flat roof building models called TPU Data measured at Wind Engineering information Centre, Tokyo Polytechnic University [68]. Here, surface mean pressure coefficients $\left(\overline{C_{p}}\right)$ on the front windward surface were compared to determine 


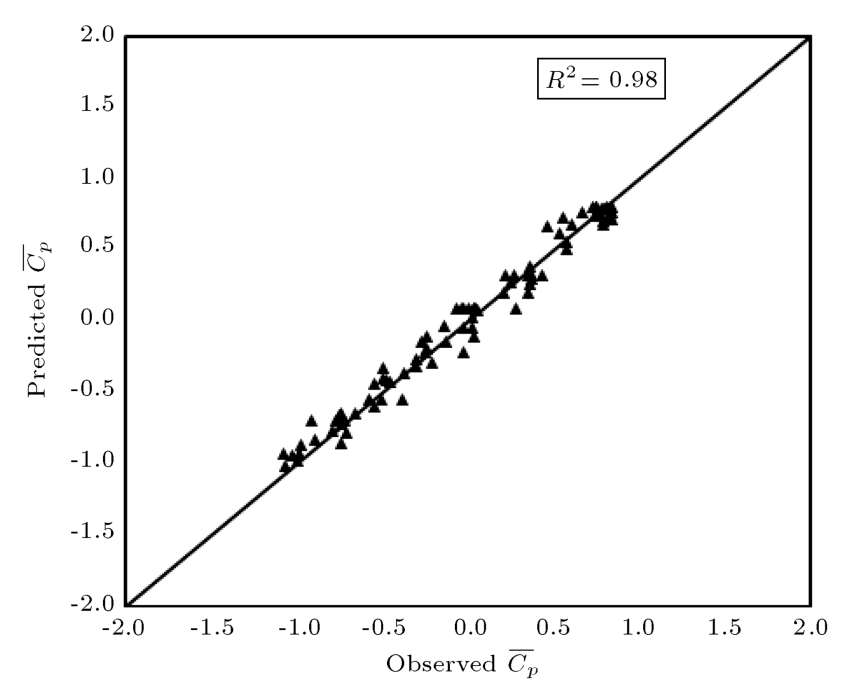

Figure 9. Comparison between observed and predicted values of $\overline{C_{p}}$ for surface 2 .

the compatibility of the developed model (Eq. (10)). The TPU data of five building models with varying wind angles, side ratios $(D / B=1,0.4,0.667,1.5$, and 2.5$)$, and height ratios $(H / B=1 / 4,2 / 4,3 / 4$, and $4 / 4)$ are used for comparative studies. The $\overline{C_{p}}$ values for wind angles $(\theta)$ from $0^{\circ}$ to $180^{\circ}$ at $30^{\circ}$ intervals were calculated by using the developed MARS

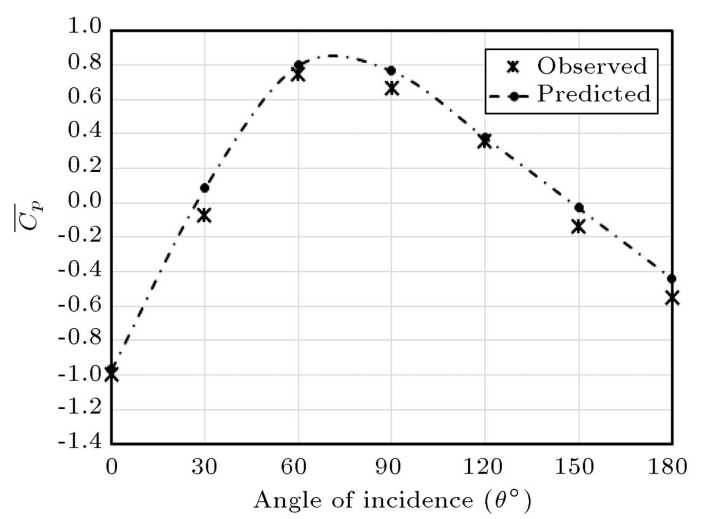

(a) $d / b=1.25, R=20$

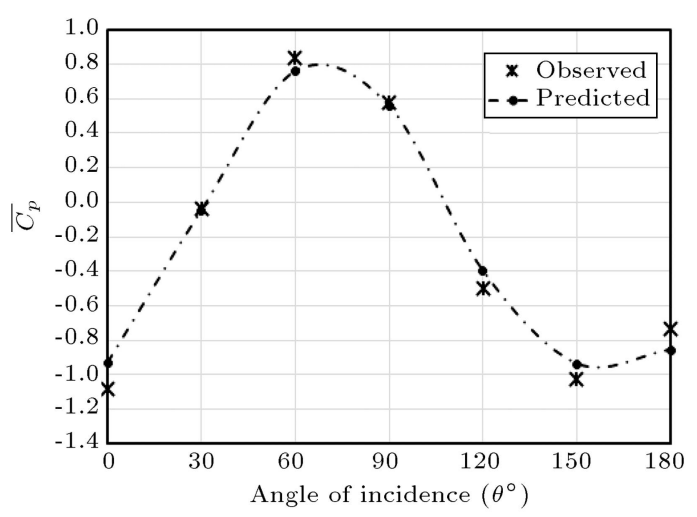

(c) $d / b=2, R=40$
Table 8. Error analysis of predicted $\overline{C_{p}}$ data using Multivariate Adaptive Regression Spline (MARS) model with Tokyo Polytechnic University (TPU) dataset.

\begin{tabular}{cccccc}
\hline ME (\%) & SD & $\boldsymbol{R}^{2}$ & MAE & RMSE & MAPE \\
\hline 6.69 & 19.05 & 0.99 & 0.06 & 0.07 & -1.95 \\
\hline
\end{tabular}

model (Eq. (10)) and compared with corresponding TPU data (presented in Figure 14). The error analysis for predicting surface mean pressure coefficient of TPU dataset was also performed in terms of Mean Percentage (ME) error, Standard Deviation (SD), coefficient of determination, MAE, RMSE, and MAPE as shown in Table 8 to check the compatibility of developed model equation.

\section{Conclusions}

From the results and discussion, the following conclusions were drawn:

- The developed model using Multivariate Adaptive Regression Spline (MARS) could be satisfactorily used to assess the surface mean pressure coefficient on the surfaces of C-shaped building model for all

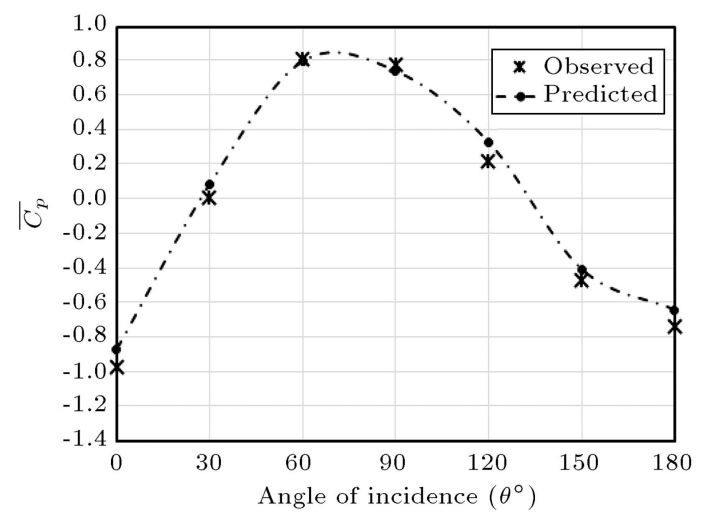

(b) $d / b=1.5, R=30$

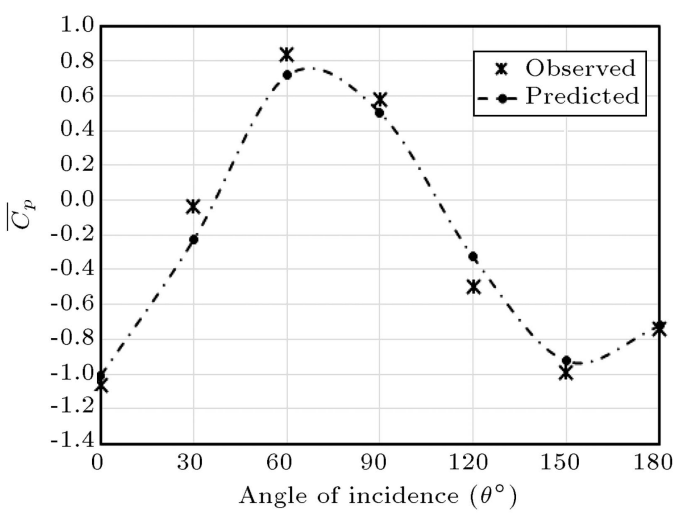

(d) $H / D=50$

Figure 10. Comparison between the predicted and observed values of $\overline{C_{p}}$ for different curvatures. 


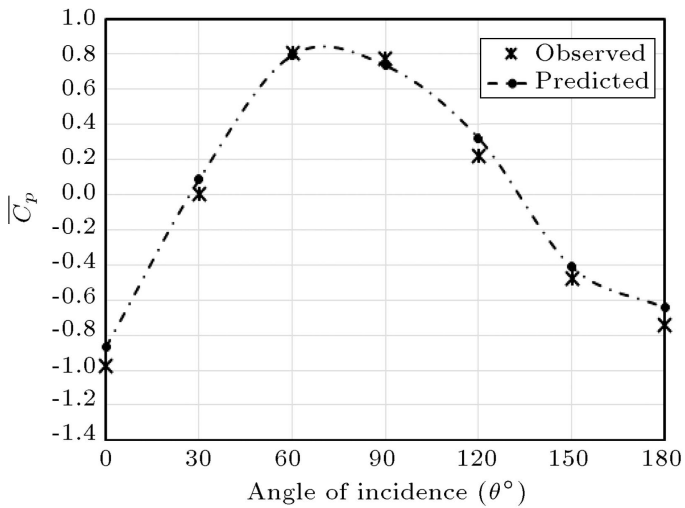

(a) $D / B=1, d / b=1.5$

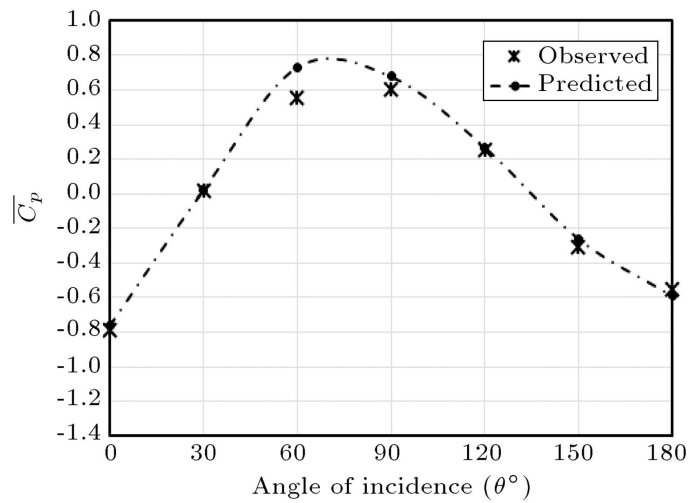

(c) $D / B=0.83, d / b=1.16$

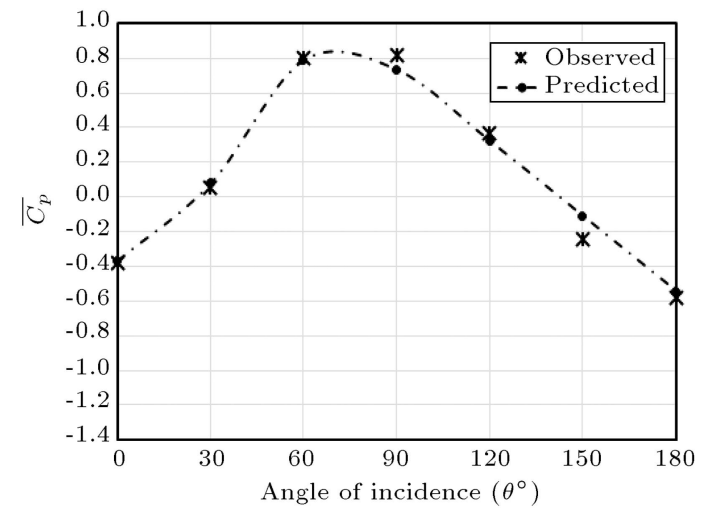

(b) $D / B=0.92, d / b=1.33$

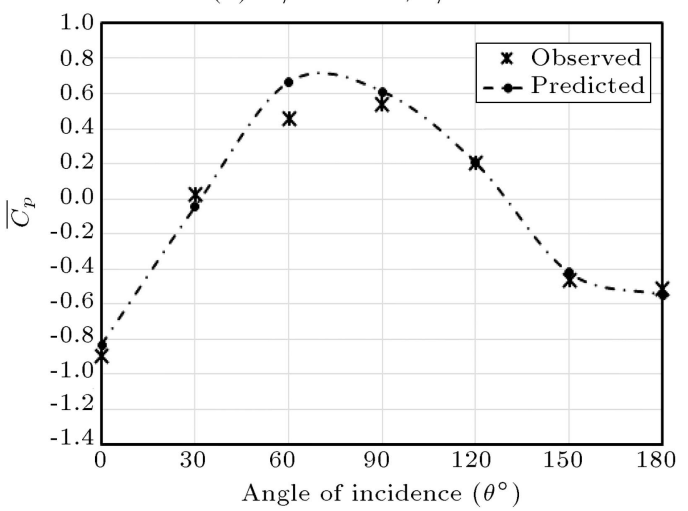

(d) $D / B=0.75, d / b=1$

Figure 11. Comparison between the predicted and observed values of $\overline{C_{p}}$ at frontal ratio.

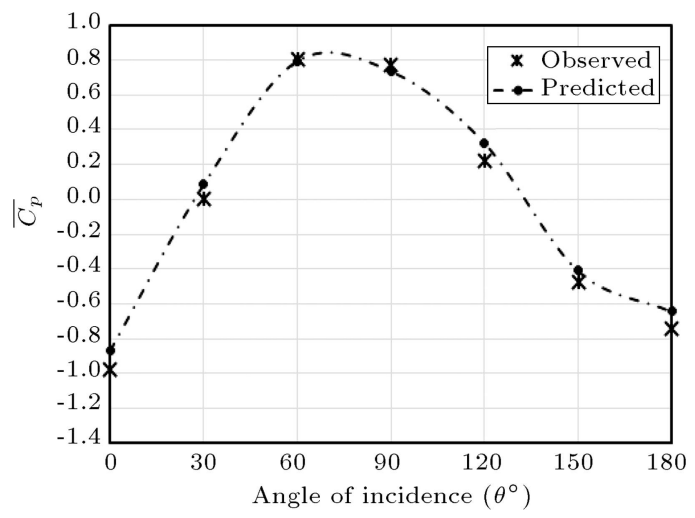

(a) $D / B=1, d / b=1.5$

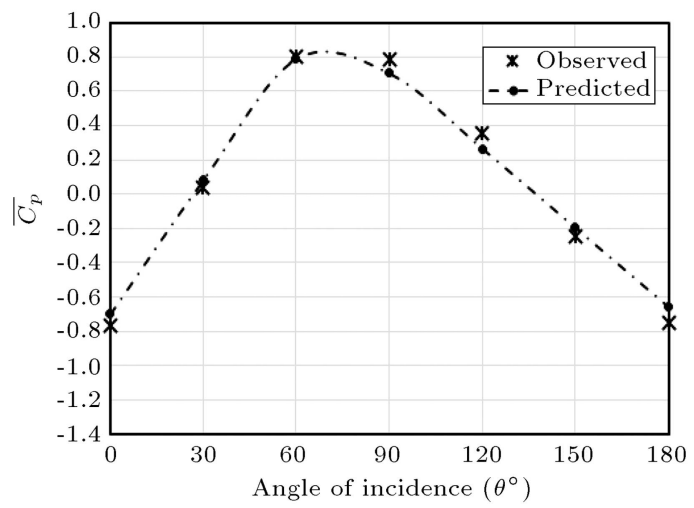

(c) $D / B=1.2, d / b=2.25$

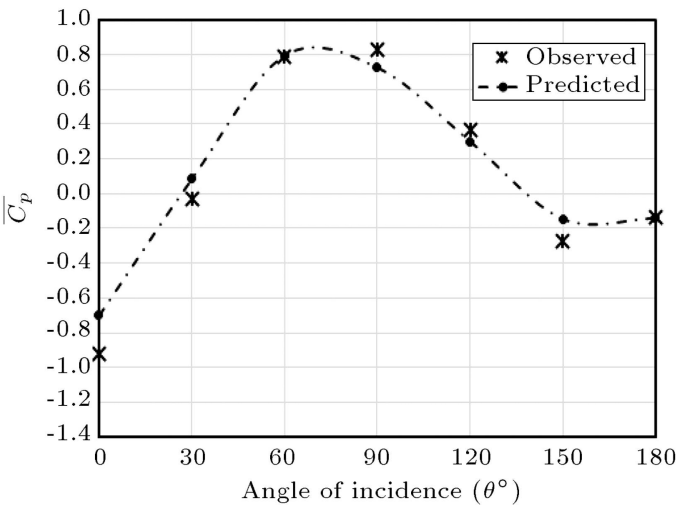

(b) $D / B=1.09, d / b=1.8$

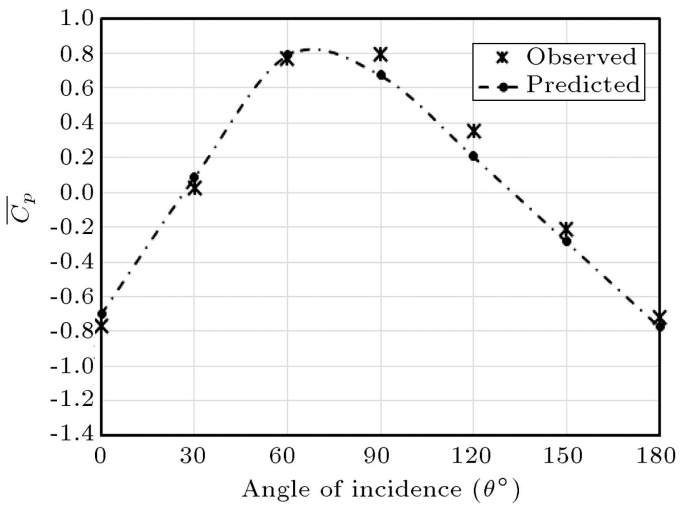

(d) $D / B=1.33, d / b=3$

Figure 12. Comparison between the predicted and observed values of $\overline{C_{p}}$ at side ratio. 


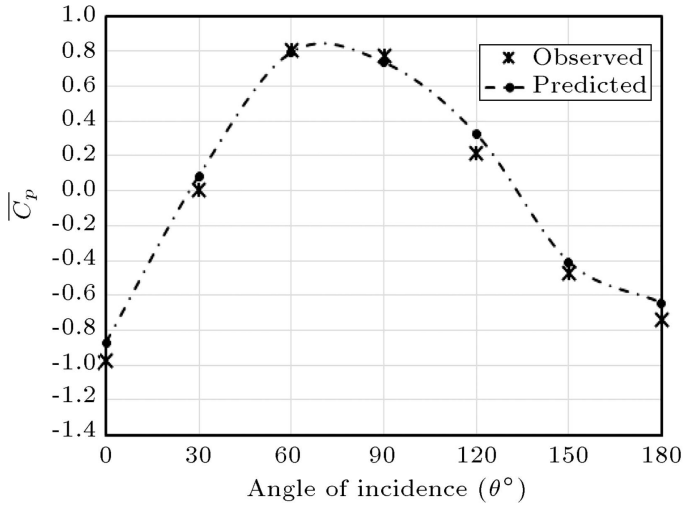

(a) $H / D=0.67$

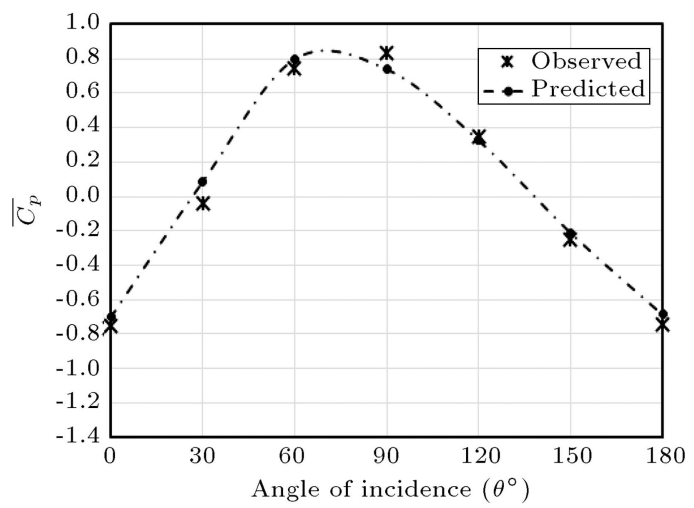

(c) $H / D=0.5$

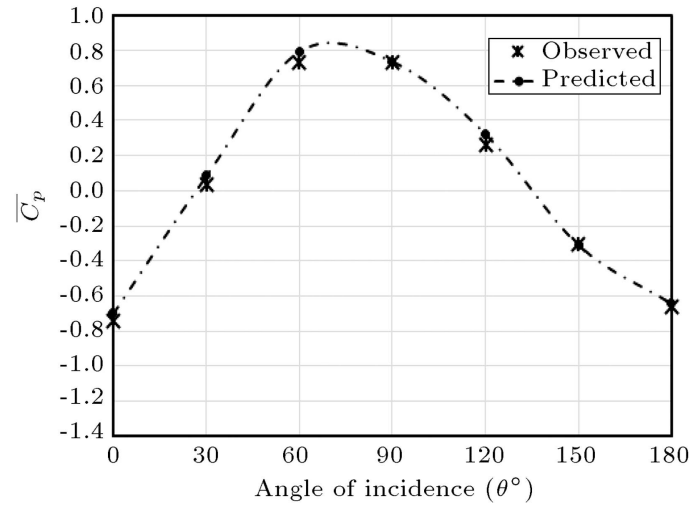

(b) $H / D=0.58$

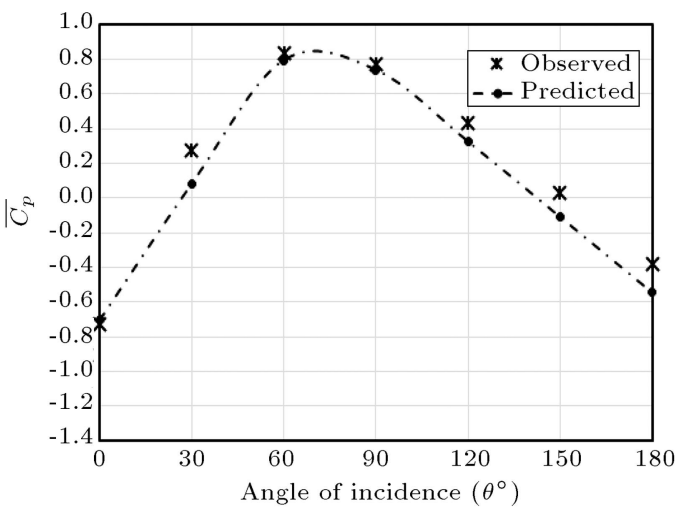

(d) $H / D=0.42$

Figure 13. Comparison between the predicted and observed values of $\overline{C_{p}}$ at height ratio.

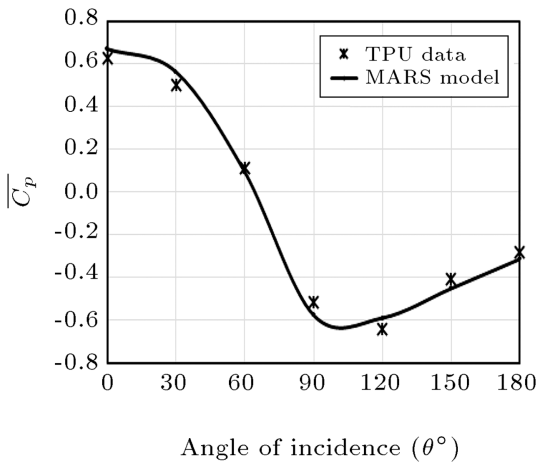

(a) $D / B=1$

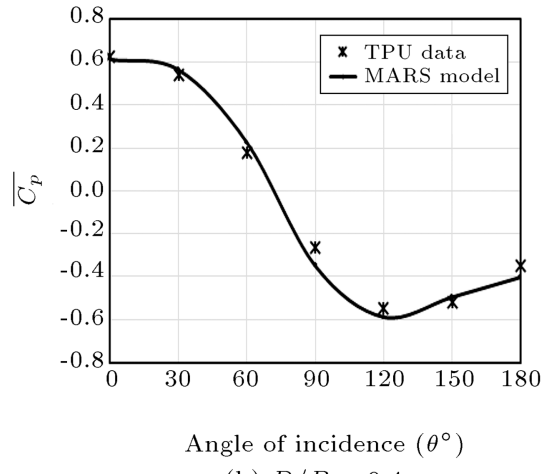

(b) $D / B=0.4$

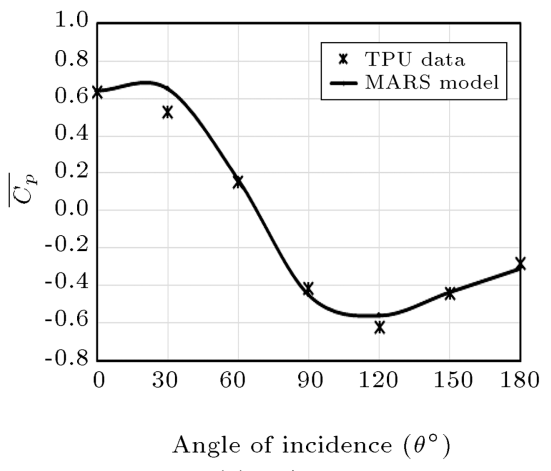

(c) $D / B=0.667$

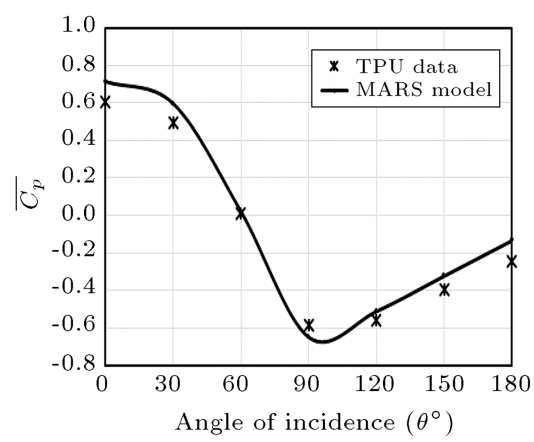

(d) $D / B=1.5$

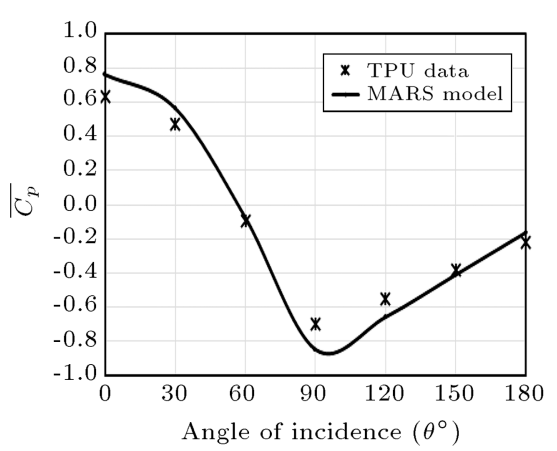

(e) $D / B=2.5$

Figure 14. Comparison between Multivariate Adaptive Regression Spline (MARS) predicted $\overline{C_{p}}$ values and Tokyo Polytechnic University (TPU) Dataset on surface 1. 
the cases with wind angle of incidence, curvatures, and aspect ratio;

- The predictions of surface mean pressure coefficient values obtained by using the developed model were in good agreement with the corresponding experimental data;

- The predicted values of $\overline{C_{p}}$ using the developed MARS model were in good agreement with those by the previously developed $\mathrm{S} \& \mathrm{C}$ and M\&P model equations;

- The values of the mean percentage error, mean absolute error, mean absolute percentage error, and root mean square error of the predicted results by the MARS model were the least as compared to predictions by $\mathrm{S} \& \mathrm{C}$ and $\mathrm{M} \& \mathrm{P}$ models. It was shown that the proposed model predicted the surface mean pressure coefficient to be closer to the experimental data;

- The developed MARS model was found compatible with the actual Tokyo Polytechnic University (TPU) dataset.

\section{Acknowledgements}

The authors express a deep sense of gratefulness to the Head of the Department of Aerospace Engineering, Indian Institute of Technology Kharagpur, India for permitting and providing facilities to carry out the experiments. The authors are also grateful to the Head of the Department of Civil Engineering, NIT Rourkela and National Institute of Technology Rourkela for the support.

\section{Nomenclature}

$\begin{array}{ll}D & \text { Overall depth of the model }(\mathrm{mm}) \\ B & \text { Overall breadth of the model }(\mathrm{mm}) \\ H & \text { Height of the model }(\mathrm{mm}) \\ d & \text { Depth of the model }(\mathrm{mm}) \\ b & \text { Breadth of the model }(\mathrm{mm}) \\ R & \text { Radius of Curvature }(\mathrm{mm}) \\ \theta & \text { Angle of incidence (degree) } \\ C_{p} & \text { Pressure coefficient } \\ \overline{C_{p}} & \text { Surface mean pressure coefficient } \\ p & \text { Mean pressure data obtained } \\ P_{o} & \text { experimentally } \\ P_{\infty} & \text { Total pressure in the settling chamber } \\ R^{2} & \text { Static pressure in the reference tube } \\ B_{i}(x) & \text { Coefficient of regression } \\ C_{i} & \text { Basic functions }\end{array}$

MARS Multivariate Adaptive Regression Spline

DSA Digital Sensor Array

TPU Tokyo Polytechnic University

GCV Generalized Cross-Validation

RSS Residual Sum-of-Squares

ME Mean percentage Error

SD Standard Deviation

MAE Mean Absolute Error

NMAE Normalization Mean Absolute Error

RMSE Normalization Root Mean Square Error

NRMSE Root Mean Square Error

MAPE Mean Absolute Percentage Error

\section{References}

1. Lin, N., Letchford, C., Tamura, Y., Liang, B., and Nakamura, O. "Characteristics of wind forces acting on tall buildings", Journal of Wind Engineering and Industrial Aerodynamics, 93(3), pp. 217-242 (2005).

2. Macdonald, A.J., Wind Loading on Buildings, Halsted Press (1975).

3. Meroney, R.N. "Wind-tunnel modelling of the flow about bluff bodies", Journal of Wind Engineering and Industrial Aerodynamics, 29(1-3), pp. 203-223 (1988).

4. Cook, N.J. "The designer's guide to wind loading of building structures", Building Research Establishment Report, Part 2: Static Structures, Butterworths, London (1990).

5. Suresh Kumar, K., Irwin, P.A., and Davies, A. "Design of tall building for wind: wind tunnel vs. codes/standards", Third National Conference on Wind Engineering, Calcutta, India, pp. 318-325 (2006).

6. Stathopoulos, T. and Zhou, Y.S. "Numerical simulation of wind-induced pressures on buildings of various geometries", Computational Wind Engineering, 1, Elsevier, pp. 419-430 (1993).

7. Zhou, Y. and Stathopoulos, T. "A new technique for the numerical simulation of wind flow around buildings", Journal of Wind Engineering and Industrial Aerodynamics, 72, pp. 137-147 (1997).

8. Ahmad, S. and Kumar, K. "Interference effects on wind loads on low-rise hip roof buildings", Engineering Structures, 23(12), pp. 1577-1589 (2001).

9. Ho, T.C.E., Surry, D., and Davenport, A.G. "The variability of low building wind loads due to surrounding obstructions", Journal of Wind Engineering and Industrial Aerodynamics, 36, pp. 161-170 (1990).

10. Lou, W., Jin, H., Chen, Y., Cao, L., and Yao, J. "Wind tunnel test study on wind load characteristics for double-skin facade building with rectangular shape", Journal of Building Structure, 26(1), pp. 65-70 (2005). 
11. Lu, S., Chen, S.F., Li, J.H., and Jiao, Y.F. "Numerical study on the effects of curved annex on the wind loads on a spherical tall building", Engineering Mechanics, 2, p. 021 (2007).

12. Chakraborty, S., Dalui, S.K., and Ahuja, A.K. "Experimental and numerical study of surface pressure on '+' plan shape tall building", International Journal of Construction Materials and Structures, 8(3), pp. 251262 (2013).

13. Gomes, M.G.R., Rodrigues, A.M., and Mendes, P. "Experimental and numerical study of wind pressures on irregular-plan shapes", Journal of Wind Engineering and Industrial Aerodynamics, 93(10), pp. 741-756 (2005).

14. Amin, J.A. and Ahuja, A.K. "Experimental study of wind pressures on irregular plan shape buildings", BBAA VI International Colloquium on: Bluff Bodies Aerodynamics and Applications, Milano, Italy, pp. 2024 (2008).

15. Amin, J.A. and Ahuja, A.K. "Experimental study of wind-induced pressures on buildings of various geometries", International Journal of Engineering, Science and Technology, 3(5), pp. 1-19 (2011). https://www.ajol.info/index.php/ijest/issue/view/ 8314

16. Kim, Y.C. and Kanda, J. "Wind pressures on tapered and set-back tall buildings", Journal of Fluids and Structures, 39, pp. 306-321 (2013).

17. Chakraborty, S., Dalui, S.K., and Ahuja, A.K. "Wind load on irregular plan shaped tall building-a case study", Wind Struct., 19(1), pp. 59-73 (2014).

18. Bhattacharyya, B., Dalui, S.K., and Ahuja, A.K. "Wind induced pressure on E plan shaped tall buildings", Jordon Journal of Civil Engineering, 8(2), pp. 120-134 (2014).

19. Bhattacharyya, B. and Dalui, S.K. "Investigation of mean wind pressures on 'E' plan shaped tall building", Wind and Structures, 26(2), pp. 99-114 (2018).

20. Yi, J. and Li, Q.S. "Wind tunnel and full-scale study of wind effects on a super-tall building", Journal of Fluid Structure, 58, pp. 236-253 (2015).

21. $\mathrm{Li}, \mathrm{Y}$. and $\mathrm{Li}, \mathrm{Q}$. "Across-wind dynamic loads on L-shaped tall buildings", Wind Structure, 23(5), pp. 385-403 (2016).

22. Mallick, M., Mohanta, A., Kumar, A., and Raj, V. "Modelling of wind pressure coefficients on Cshaped building models", Modelling and Simulation in Engineering, 2018, Article ID 6524945, 13 pages (2018). https://doi.org/10.1155/2018/6524945

23. Akins, R.E. "Wind pressures on buildings", CER; 76/77-15 (1976).

24. Walton, G.N. "Airflow and multiroom thermal analysis", ASHRAE Transactions, 88, pp. 78-91 (1982).

25. Walker, I.S. and Wilson, D.J. "Evaluating models for superposition of wind and stack effect in air infiltration", Building and Environment, 28(2), pp. 201-210 (1993).
26. Ginger, J.D. and Letchford, C.W. "Net pressures on a low-rise full-scale building", Journal of Wind Engineering and Industrial Aerodynamics, 83(1-3), pp. 239-250 (1999).

27. Ohkuma, T., Marukawa, H., Niihori, Y., and Kato, N. "Full-scale measurement of wind pressures and response accelerations of a high-rise building", Journal of Wind Engineering and Industrial Aerodynamics, 38(2-3), pp. 185-196 (1991).

28. Swami, M.V. and Chandra, S. "Procedures for calculating natural ventilation airflow rates in buildings", ASHRAE Final Report FSEC-CR-163-86, ASHRAE Research Project (1987).

29. Swami, M.V. and Chandra, S. "Correlations for pressure distribution on buildings and calculation of natural-ventilation airflow", ASHRAE Transactions, 94(3112), pp. 243-266 (1988).

30. Grosso, M. "Wind pressure distribution around buildings: a parametrical model", Energy and Buildings, 18(2), pp. 101-131 (1992).

31. Crawley, D.B., Lawrie, L.K., Winkelmann, F.C., Buhl, W.F., Huang, Y.J., Pedersen, C.O., Strand, R.K., Liesen, R.J., Fisher, D.E., and Witte, M.J. "EnergyPlus: creating a new-generation building energy simulation program", Energy and Buildings, 33(4), pp. 319-331 (2001).

32. Cook, N., Designers' Guide to EN 1991-1-4 Eurocode 1: Actions on Structures, general actions part 1-4. Wind actions, Thomas Telford Publishing (2007).

33. Costola, D., Blocken, B., and Hensen, J.L.M. "Overview of pressure coefficient data in building energy simulation and airflow network programs", Building and Environment, 44(10), pp. 2027-2036 (2009).

34. Costola, D., Blocken, B., Ohba, M., and Hensen, J.L.M. "Uncertainty in airflow rate calculations due to the use of surface-averaged pressure coefficients", Energy and Buildings, 42(6), pp. 881-888 (2010).

35. Muehleisen, R.T. and Patrizi, S. "A new parametric equation for the wind pressure coefficient for low-rise buildings", Energy and Buildings, 57, pp. 245-249 (2013).

36. Deo, R.C. and Sahin, M. "Application of the extreme learning machine algorithm for the prediction of monthly effective drought index in eastern Australia", Atmospheric Research, 153, pp. 512-525 (2015).

37. Samadi, M., Jabbari, E., Azamathulla, H.M., and Mojallal, M. "Estimation of scour depth below free overfall spillways using multivariate adaptive regression splines and artificial neural networks", Engineering Applications of Computational Fluid Mechanics, 9(1), pp. 291-300 (2015).

38. Suman, S., Mahamaya, M., and Das, S.K. "Prediction of maximum dry density and unconfined compressive strength of cement stabilised soil using artificial intelligence techniques", International Journal of Geosynthetics and Ground Engineering, 2(2), p. 11 (2016). 
39. Mehdizadeh, S., Behmanesh, J., and Khalili, K. "Application of gene expression programming to predict daily dew point temperature", Applied Thermal Engineering, 112, pp. 1097-1107 (2017).

40. Milukow, H.A., Binns, A.D., Adamowski, J., Bonakdari, H., and Gharabaghi, B. "Estimation of the darcy-weisbach friction factor for ungauged streams using gene expression programming and extreme learning machines", Journal of Hydrology, 568, pp. 311-321 (2018).

41. Mohanta, A., Patra, K.C., and Sahoo, B. "Anticipate Manning's coefficient in meandering compound channels", Hydrology, 5(3), p. 47 (2018).

42. Najafzadeh, M., Rezaie-Balf, M., and Tafarojnoruz, A. "Prediction of riprap stone size under overtopping flow using data-driven models", International Journal of River Basin Management, 16(4), pp. 1-8 (2018).

43. Shende, S. and Chau, K.W. "Forecasting safe distance of a umping well for effective riverbank filtration", Journal of Hazardous, Toxic, and Radioactive Waste, 23(2), p. 04018040 (2018).

44. Varvani, J. and Khaleghi, M.R. "A performance evaluation of neuro-fuzzy and regression methods in estimation of sediment load of selective rivers", Acta Geophysica, 67(1), pp. 205-214 (2018). https://doi.org/10.1007/s11600-018-0228-9

45. Sheikh Khozani, Z., Bonakdari, H., and Zaji, A.H. "Mean bed shear stress estimation in a rough rectangular channel using a hybrid genetic algorithm based on an artificial neural network and genetic programming", Scientia Iranica, 25(1), pp. 152-161 (2018).

46. Bui, D.T., Hoang, N.D., and Samui, P. "Spatial pattern analysis and prediction of forest fire using new machine learning approach of multivariate adaptive regression splines and differential flower pollination optimization: a case study", at Lao Cai province (Viet Nam). Journal of Environmental Management, 237, pp. 476-487 (2019).

47. Zaji, A.H., Bonakdari, H., and Shamshirband, S. "Standard equations for predicting the discharge coefficient of a modified high-performance side weir", Scientia Iranica, 25(3), pp. 1057-1069 (2018).

48. Samui, P., Das, S., and Kim, D. "Uplift capacity of suction caisson in clay using multivariate adaptive regression spline", Ocean Engineering, 38(17-18), pp. 2123-2127 (2011).

49. Samui, P. and Kurup, P. "Multivariate adaptive regression spline (MARS) and least squares support vector machine (LSSVM) for OCR prediction", Soft Computing, 16(8), pp. 1347-1351 (2012).

50. Samui, P. "Multivariate adaptive regression spline (Mars) for prediction of elastic modulus of jointed rock mass", Geotechnical and Geological Engineering, 31(1), pp. 249-253 (2013).
51. Cheng, M.Y. and Cao, M.T. "Accurately predicting building energy performance using evolutionary multivariate adaptive regression splines", Applied Soft Computing, 22, pp. 178-188 (2014).

52. Koc, E.K. and Bozdogan, H. "Model selection in multivariate adaptive regression splines (MARS) using information complexity as the fitness function", $M a$ chine Learning, 101(1-3), pp. 35-58 (2015).

53. Zhang, W. and Goh, A.T. "Multivariate adaptive regression splines and neural network models for prediction of pile drivability", Geoscience Frontiers, 7(1), pp. $45-52$ (2016).

54. Mukhopadhyay, T. "A multivariate adaptive regression splines based damage identification methodology for web core composite bridges including the effect of noise", Journal of Sandwich Structures \& Materials, 20(7), pp. 885-903 (2017). https://doi.org/10.1177/1099636216682533

55. Bhattacharya, S., Murakonda, P., and Das, S. "Prediction of uplift capacity of suction caisson in clay using functional network and multivariate adaptive regression spline", Scientia Iranica, 25(2), pp. 517-531 (2018).

56. Mirabbasi, R., Kisi, O., Sanikhani, H., and Meshram, S.G. "Monthly long-term rainfall estimation in Central India using M5Tree, MARS, LSSVR, ANN and GEP models", Neural Computing and Applications, 31(10), pp. 6843-6862 (2019). https://doi.org/10.1007/s00521-018-3519-9

57. Goh, A.T.C., Zhang, W., Zhang, Y., Xiao, Y., and Xiang, Y. "Determination of earth pressure balance tunnel-related maximum surface settlement: a multivariate adaptive regression splines approach", Bulletin of Engineering Geology and the Environment, 77(2), pp. $489-500$ (2018).

58. Zhang, W., Zhang, R., and Goh, A.T. "Multivariate adaptive regression splines approach to estimate lateral wall deflection profiles caused by braced excavations in clays", Geotechnical and Geological Engineering, 36(2), pp. 1349-1363 (2018).

59. Friedman, J.H. "Multivariate adaptive regression splines", Annals of Statistics, 19(1), pp. 1-67 (1991). https://doi.org/10.1214/aos/1176347963

60. Friedman, J.H. and Roosen, C.B., An Introduction to Multivariate Adaptive Regression Splines, Sage Publications Sage CA: Thousand Oaks, CA (1995).

61. Leathwick, J.R., Rowe, D., Richardson, J., Elith, J., and Hastie, T. "Using multivariate adaptive regression splines to predict the distributions of New Zealand's freshwater diadromous fish", Freshwater Biology, 50(12), pp. 2034-2052 (2005).

62. Craven, P. and Wahba, G. "Smoothing noisy data with spline functions", Numerische Mathematik, 31(4), pp. 377-403 (1978).

63. Barati, R., Rahimi, S., and Akbari, G.H. "Analysis of dynamic wave model for flood routing in natural rivers", Water Science and Engineering, 5(3), pp. 243258 (2012). 
64. Barati, R. "Application of excel solver for parameter estimation of the nonlinear Muskingum models", KSCE Journal of Civil Engineering, 17(5), pp. 11391148 (2013).

65. Akbari, G.H. and Barati, R. "Comprehensive analysis of flooding in unmanaged catchments", Proceedings of the Institution of Civil Engineers-Water Management, pp. 229-238 (2012).

66. Gandomi, A.H., Yun, G.J., and Alavi, A.H. "An evolutionary approach for modelling of shear strength of RC deep beams", Materials and Structures, 46(12), pp. 2109-2119 (2013).

67. Ebtehaj, I., Bonakdari, H., Zaji, A.H., Azimi, H., and Khoshbin, F. "GMDH-type neural network approach for modeling the discharge coefficient of rectangular sharp-crested side weirs", Engineering Science and Technology, an International Journal, 18(4), pp. 746757 (2015).

68. Bre, F., Gimenez, J.M., and Fachinotti, V.D. "Prediction of wind pressure coefficients on building surfaces using artificial neural networks", Energy and Buildings, 158, pp. 1429-1441 (2018).

\section{Biographies}

Monalisa Mallick is a Doctoral Research Fellow of the Department of Civil Engineering, National Institute of Technology Rourkela, India. She received a post-graduate degree in Water Resources Engineering from the same institute in 2014. Her doctoral research topic is experimental and numerical investigation of wind induced pressure on C-shaped building models. Her areas of research interests include building engineering, aerodynamics, computational fluid dynamics, artificial intelligence technique, wind engineering, and water resources engineering.

Abinash Mohanta is a Senior Assistant Professor of the School of Mechanical Engineering, Vellore Institute of Technology Vellore (VIT), Tamil-Nadu, India. He received his MTech and PhD degrees in Civil Engineering from the National Institute of Technology (NIT) Rourkela, Odisha, India in 2014 and 2019, respectively. He was the recipient of the Union Ministry of Water Resources: Department of Irrigation Prize in 2019 from "The Institute of Engineers (India)" for his contributions to the field of open channel flow in 2018. His current research interests include water resources engineering, open channel flow hydraulics, computational fluid dynamics, aerodynamics, experimental and numerical river hydro dynamic modeling, experimental fluid mechanics and modeling, river and steam flow modeling, surface water hydrology and hydraulics, and artificial intelligence technique.

Awadhesh Kumar is a Professor of the Department of Civil Engineering, National Institute of Technology Rourkela, India. He was involved in teaching, research and other activities of the department. He received his $\mathrm{PhD}$ degree in Civil Engineering from National Institute of Technology Rourkela in 2004. He continued his research work in fluid dynamics, aerodynamics, and water resources engineering. Presently, he is a Professor in Water Resources Engineering at Civil Engineering Department, National Institute of Technology, Rourkela and has published more than 40 papers in National, International Journals and Conferences. 